\title{
Consistent dust and gas models for protoplanetary disks
}

\section{Chemical networks and rates}

\author{
I. Kamp ${ }^{1}$, W.-F. Thi ${ }^{2}$, P. Woitke ${ }^{3}$, C. Rab ${ }^{4}$, S. Bouma ${ }^{1}$, and F. Ménard ${ }^{5}$ \\ 1 Kapteyn Astronomical Institute, University of Groningen, Postbus 800, 9700 AV Groningen, The Netherlands \\ 2 Max Planck Institute for Extraterrestrial Physics, Giessenbachstrasse, 85741 Garching, Germany \\ 3 SUPA, School of Physics \& Astronomy, University of St. Andrews, North Haugh, St. Andrews, KY16 9SS, UK \\ 4 University of Vienna, Department for Astrophysics, Türkenschanzstr.17, 1180 Vienna, Austria \\ 5 University of Grenoble Alpes, CNRS, IPAG, 38000 Grenoble, France
}

Received 3 January 2017 / Accepted 20 July 2017

\begin{abstract}
Aims. We aim to define a small and large chemical network which can be used for the quantitative simultaneous analysis of molecular emission from the near-IR to the submm. We also aim to revise reactions of excited molecular hydrogen, which are not included in UMIST, to provide a homogeneous database for future applications.

Methods. We have used the thermo-chemical disk modeling code ProDiMo and a standard T Tauri disk model to evaluate the impact of various chemical networks, reaction rate databases and sets of adsorption energies on a large sample of chemical species and emerging line fluxes from the near-IR to the submm wavelength range.

Results. We find large differences in the masses and radial distribution of ice reservoirs when considering freeze-out on bare or polar ice coated grains. Most strongly the ammonia ice mass and the location of the snow line (water) change. As a consequence molecules associated to the ice lines such as $\mathrm{N}_{2} \mathrm{H}^{+}$change their emitting region; none of the line fluxes in the sample considered here changes by more than $25 \%$ except $\mathrm{CO}$ isotopologues, $\mathrm{CN}$ and $\mathrm{N}_{2} \mathrm{H}^{+}$lines. The three-body reaction $\mathrm{N}_{+} \mathrm{H}_{2}+\mathrm{M}$ plays a key role in the formation of water in the outer disk. Besides that, differences between the UMIST 2006 and 2012 database change line fluxes in the sample considered here by less than a factor of two (a subset of low excitation CO and fine structure lines stays even within 25\%); exceptions are $\mathrm{OH}, \mathrm{CN}, \mathrm{HCN}, \mathrm{HCO}^{+}$and $\mathrm{N}_{2} \mathrm{H}^{+}$lines. However, different networks such as OSU and KIDA 2011 lead to pronounced differences in the chemistry inside 100 au and thus affect emission lines from high excitation $\mathrm{CO}, \mathrm{OH}$ and $\mathrm{CN}$ lines. $\mathrm{H}_{2}$ is easily excited at the disk surface and state-to-state reactions enhance the abundance of $\mathrm{CH}^{+}$and to a lesser extent $\mathrm{HCO}^{+}$. For sub-mm lines of $\mathrm{HCN}_{2} \mathrm{~N}_{2} \mathrm{H}^{+}$ and $\mathrm{HCO}^{+}$, a more complex larger network is recommended.

Conclusions. More work is required to consolidate data on key reactions leading to the formation of water, molecular ions such as $\mathrm{HCO}^{+}$and $\mathrm{N}_{2} \mathrm{H}^{+}$as well as the nitrogen chemistry. This affects many of the key lines used in the interpretation of disk observations. Differential analysis of various disk models using the same chemical input data will be more robust than the interpretation of absolute fluxes.
\end{abstract}

Key words. astrochemistry - molecular data - protoplanetary disks - methods: numerical

\section{Introduction}

Observations often detect a multitude of simple molecules which have bright emission lines in protoplanetary disks such as $\mathrm{CO}$, $\mathrm{HCO}^{+}, \mathrm{HCN}, \mathrm{CN}, \mathrm{N}_{2} \mathrm{H}^{+}, \mathrm{H}_{2} \mathrm{CO}, \mathrm{CH}^{+}$(e.g., Thi et al. 2004; Dutrey et al. 2007; Öberg et al. 2010; Thi et al. 2011a; Qi et al. 2013a). Even though studying differences in the molecular content of disks is interesting in its own right, molecules are frequently used as tracers of disk properties, such as outer gas radius (e.g., Panić \& Hogerheijde 2009), the position of the CO ice line (e.g., Qi et al. 2013b), the ionization degree (e.g., Qi et al. 2003), the irradiation by X-rays (e.g., Aikawa \& Herbst 2001) and the deuterium fractionation (e.g., Ceccarelli et al. 2005).

Due to the importance of molecular lines for protoplanetary disk research, several studies have focussed on the size of chemical networks and the uncertainties in chemical rates. Semenov et al. (2004) find that the midplane and the ionized surface layer can be described using very small networks, while the intermediate layer, where most of the ion-molecule chemistry happens, requires large networks with of the order of
100 species. Vasyunin et al. (2004) varied the rate constants within the uncertainties using a Monte Carlo approach and conditions representative of diffuse and dark clouds. In dark clouds, they find abundance changes of less than $0.5 \mathrm{dex}$ for simple species such as $\mathrm{N}_{2} \mathrm{H}^{+}, \mathrm{HCO}^{+}$, while $\mathrm{HCN}$ can change up to 1 dex. Interestingly, $\mathrm{CO}$ is among the most robust species. Vasyunin et al. (2008) expanded this study to protoplanetary disk conditions. Again, $\mathrm{CO}$ is the most robust species while $\mathrm{HCN}, \mathrm{N}_{2} \mathrm{H}^{+}$, and $\mathrm{HCO}^{+}$column densities can typically vary by a factor 2.5-3. Local changes can, however, be larger than this.

Thermo-chemical disk models often use a single network throughout the entire disk. When comparing such models to a set of observational data including molecular emission lines, we often rely in a first step on simple molecules such as $\mathrm{CO}$ and HCN. For those molecules, the chemistry is simple, resulting in robust model predictions. The chemical network used in this step should be small and fast to solve in order to allow the computation of larger model grids or the use of evolutionary search strategies to derive basic properties of the disk such as the dust mass, the mass of CO gas, radial extent of the disk, 
and the amount of flaring. In a second step, based on the previously found disk model, species with a more complex chemistry can be studied using larger chemical networks. It is important however to note that the chemical network is only one aspect in the interpretation of line observations. The other one, which is not addressed in this work, is the calculation of the excitation of the molecule which can be limited by the availability of molecular data (mainly collision cross sections), the complexity of IR and UV pumping or resonance scattering for optically thick lines (e.g., Cernicharo et al. 2009; Bethell \& Bergin 2011; Kamp et al. 2013; Thi et al. 2013).

We develop in this paper simple rules for the construction of chemical networks that avoid artificial sinks and ensure links between various sub-networks such as the carbon, oxygen and nitrogen chemistry. We use a standard T Tauri disk model from Woitke et al. (2016) to study the impact of the size of the network, different chemical databases and ice adsorption scenarios on the species mass and emission from a representative sample of atomic and molecular lines (Sect. 2). Woitke et al. (2016) show that time-dependent chemistry has little effect on the resulting line fluxes at ages beyond 0.5 Myr. Hence, we focus here entirely on stationary chemistry. In Sect. 3, we discuss how changes in the UMIST database and the use of other databases affect the disk chemistry and line emission (Sects. 3.2 and 3.3). We investigate the role of three-body reactions for water chemistry (Sect. 3.3) and how the composition of the grains (bare or polar ices) affects the various ices reservoirs and emission lines connected to them (Sect. 3.4). We study the importance of reactions with excited molecular hydrogen (Sect. 3.5) and we end with assessing which emission lines require the use of larger chemical networks (Sect. 3.6).

\section{Modeling}

\subsection{The disk model}

We chose for this study a parametrized disk structure representative of a typical T Tauri star. The full model is described in Woitke et al. (2016). Table 1 repeats only the most important stellar and disk parameters.

To calculate the two dimensional physical and chemical structure, we used the radiation thermo-chemical disk code ProDiMo (Woitke et al. 2009a; Kamp et al. 2010; Thi et al. $2011 b)$. The disk structure was set up using a tapered edge and mildly flaring geometry $(\beta=1.15)$. It extends from 0.07 to $700 \mathrm{au}$ (characteristic radius at $100 \mathrm{au}$ ) and contains a gas mass of $0.033 M_{\odot}$. The dust grain opacities were calculated using hollow spheres and a mixture of $60 \%$ silicates and $15 \%$ amorphous carbon with $25 \%$ vacuum (Min et al. 2016b) and we use the canonical dust-to-gas mass ratio of 0.01 .

Here we have used a model series where we vary the base set of reaction rates, the set of adsorption energies, and the size of the chemical network using stationary chemistry. The reaction rate databases are UMIST2012 (McElroy et al. 2013), UMIST2006 (Woodall et al. 2007), OSU (Ohio State University chemical network from Eric Herbst) and KIDA2011 (Wakelam et al. 2012). Three sets of adsorption energies are taken from Aikawa et al. (1996), Garrod \& Herbst (2006), and UMIST2012 (McElroy et al. 2013). The adsorption energies will be discussed in more detail in Sect. 3.4. The rules for compiling the small and large chemical network are provided in the next subsection. Table 2 describes the entire model series.

Since the disk chemistry and heating and cooling balance are intimately coupled, we fixed the gas temperature structure
Table 1. Basic model parameters for the standard T Tauri disk.

\begin{tabular}{lll}
\hline \hline Quantity & Symbol & Value \\
\hline Stellar mass & $M_{*}$ & $0.7 M_{\odot}$ \\
Effective temperature & $T_{\text {eff }}$ & $4000 \mathrm{~K}$ \\
Stellar luminosity & $L_{*}$ & $1.0 L_{\odot}$ \\
FUV excess & $f_{\mathrm{UV}}$ & 0.01 \\
& $p_{\mathrm{UV}}$ & 1.3 \\
Cosmic ray ionization rate & $\zeta_{\mathrm{CR}}$ & $1.7 \times 10^{-17} \mathrm{~s}^{-1}$ \\
Chemical heating efficiency & $\gamma^{\text {chem }}$ & 0.2 \\
\hline Disk gas mass ${ }^{1}$ & $M_{\text {gas }}$ & $0.033 M_{\odot}$ \\
dust-to-gas mass ratio & $\delta$ & 0.01 \\
Inner disk radius & $R_{\text {in }}$ & $0.07 \mathrm{au}$ \\
Outer disk radius & $R_{\text {out }}$ & $700 \mathrm{au}$ \\
Tapered edge radius & $R_{\text {taper }}$ & $100 \mathrm{au}$ \\
Radial column density power index & $\epsilon$ & 1.0 \\
Reference radius & $R_{0}$ & $100 \mathrm{au}$ \\
Scale height at $R_{0}$ & $H_{0}$ & $10.0 \mathrm{au}$ \\
Disk flaring power index & $\beta$ & 1.15 \\
\hline Minimum dust particle radius & $a_{\min }$ & $0.05 \mu \mathrm{m}$ \\
Maximum dust particle radius & $a_{\text {max }}$ & $3000.0 \mu \mathrm{m}$ \\
Dust size distribution power index & $a_{\text {pow }}$ & 3.5 \\
\hline
\end{tabular}

Notes. ${ }^{(1)}$ The disk mass is a factor 3.3 higher than in the original Woitke et al. (2016) model. ${ }^{(2)}$ The outer radius is defined as the radius where the surface density column drops to $N_{\langle\mathrm{H}\rangle, \text { ver }}=10^{20} \mathrm{~cm}^{-2}$.

Table 2. Series of disk models.

\begin{tabular}{|c|c|c|c|}
\hline Model & $E_{\text {ads }}$ & Network size, mode & Base rates \\
\hline model 1 & Aikawa & small, steady state & $\begin{array}{l}\text { UMIST2012 } \\
\text { + CL reactions }\end{array}$ \\
\hline model 2 & Aikawa & small, steady state & UMIST2006 \\
\hline model 3 & Aikawa & small, steady state & OSU \\
\hline model 4 & Aikawa & small, steady state & KIDA2011 \\
\hline model 1a & Aikawa & small, steady state & UMIST2012 \\
\hline model 5 & GH06 & small, steady state & $\begin{array}{l}\text { UMIST2012 } \\
+ \text { CL reactions }\end{array}$ \\
\hline model 6 & UMIST2012 & small, steady state & $\begin{array}{l}\text { UMIST2012 } \\
+ \text { CL reactions }\end{array}$ \\
\hline model 7 & $T$-dependent & small, steady state & $\begin{array}{l}\text { UMIST2012 } \\
\text { + CL reactions }\end{array}$ \\
\hline model 8 & UMIST2012 & large, steady state & $\begin{array}{l}\text { UMIST2012 } \\
+ \text { CL reactions }\end{array}$ \\
\hline
\end{tabular}

Notes. The columns denote the set of adsorption energies $E_{\text {ads }}$, chemical network and rate database used.

to that of the reference model 1 (UMIST2012, adsorption energies from Aikawa et al. 1996). This has allowed us to interpret changes in the chemical structure and emitted line fluxes entirely from the various chemical input data sets. The coupling of heating and cooling and chemical equations is highly non-linear, so the impact of our approximation can only be checked from additional models. We calculated a single additional model where we used the KIDA database and re-computed the gas temperature self-consistently. Our models - discussed in more detail in the next section - show that KIDA produces less water compared to UMIST in the warm surface layer stretching to a few au at gas temperatures higher than $200 \mathrm{~K}$. Indeed, the additional model shows that the gas temperature in that layer increases slightly since the water cooling is diminished with respect to the 
Table 3. Selection of elements and chemical (gas+ice) species in the small network.

\begin{tabular}{|c|c|c|}
\hline 12 elements & $\mathrm{H}, \mathrm{He}, \mathrm{C}, \mathrm{N}, \mathrm{O}, \mathrm{Ne}, \mathrm{Na}, \mathrm{Mg}, \mathrm{Si}, \mathrm{S}, \mathrm{Ar}, \mathrm{Fe}$ & \\
\hline (H) & $\mathrm{H}, \mathrm{H}^{+}, \mathrm{H}^{-}, \mathbf{H}_{2}, \mathrm{H}_{2}^{+}, \mathrm{H}_{3}^{+}, \mathrm{H}_{2}^{\mathrm{exc}}$ & 7 \\
\hline$(\mathrm{He})$ & $\mathrm{He}, \mathrm{He}^{+}$ & 2 \\
\hline$(\mathrm{C}-\mathrm{H})$ & $\mathrm{C}, \mathrm{C}^{+}, \mathrm{C}^{++}, \mathrm{CH}, \mathrm{CH}^{+}, \mathbf{C H}_{2}, \mathrm{CH}_{2}^{+}, \mathrm{CH}_{3}, \mathrm{CH}_{3}^{+}, \mathbf{C H}_{4}, \mathrm{CH}_{4}^{+}, \mathrm{CH}_{5}^{+}$ & 12 \\
\hline$(\mathrm{C}-\mathrm{N})$ & $\mathrm{CN}, \mathrm{CN}^{+}, \mathrm{HCN}, \mathrm{HCN}^{+}, \mathrm{HCNH}^{+}$ & 5 \\
\hline$(\mathrm{C}-\mathrm{O})$ & $\mathbf{C O}, \mathrm{CO}^{+}, \mathrm{HCO}, \mathrm{HCO}^{+}, \mathbf{C O}_{2}, \mathrm{CO}_{2}^{+}, \mathrm{HCO}_{2}^{+}$ & 7 \\
\hline$(\mathrm{N}-\mathrm{H})$ & $\mathrm{N}, \mathrm{N}^{+}, \mathrm{N}^{++}, \mathrm{NH}, \mathrm{NH}^{+}, \mathrm{NH}_{2}, \mathrm{NH}_{2}^{+}, \mathrm{NH}_{3}, \mathrm{NH}_{3}^{+}, \mathrm{NH}_{4}^{+}$ & 9 \\
\hline$(\mathrm{N}-\mathrm{N})$ & $\mathbf{N}_{2}, \mathrm{~N}_{2}^{+}, \mathrm{HN}_{2}^{+}$ & 3 \\
\hline$(\mathrm{N}-\mathrm{O})$ & $\mathrm{NO}, \mathrm{NO}^{+}$ & 2 \\
\hline$(\mathrm{O}-\mathrm{H})$ & $\mathrm{O}, \mathrm{O}^{+}, \mathrm{O}^{++}, \mathrm{OH}, \mathrm{OH}^{+}, \mathbf{H}_{2} \mathbf{O}, \mathrm{H}_{2} \mathrm{O}^{+}, \mathrm{H}_{3} \mathrm{O}^{+}$, & 8 \\
\hline$(\mathrm{O}-\mathrm{O})$ & $\mathbf{O}_{2}, \mathrm{O}_{2}^{+}$ & 2 \\
\hline$(\mathrm{O}-\mathrm{S})$ & $\mathrm{SO}, \mathrm{SO}^{+}, \mathrm{SO}_{2}, \mathrm{SO}_{2}^{+}, \mathrm{HSO}_{2}^{+}$ & 5 \\
\hline$(\mathrm{S}-\mathrm{H})$ & $\mathrm{S}, \mathrm{S}^{+}, \mathrm{S}^{++}$ & 3 \\
\hline$(\mathrm{Si}-\mathrm{H})$ & $\mathrm{Si}, \mathrm{Si}^{+}, \mathrm{Si}^{++}, \mathrm{SiH}, \mathrm{SiH}^{+}, \mathrm{SiH}_{2}^{+}$ & 6 \\
\hline$(\mathrm{Si}-\mathrm{O})$ & $\mathrm{SiO}, \mathrm{SiO}^{+}, \mathrm{SiOH}^{+}$ & 3 \\
\hline$(\mathrm{Na})$ & $\mathrm{Na}, \mathrm{Na}^{+}, \mathrm{Na}^{++}$ & 3 \\
\hline$(\mathrm{Mg})$ & $\mathrm{Mg}, \mathrm{Mg}^{+}, \mathrm{Mg}^{++}$ & 3 \\
\hline$(\mathrm{Fe})$ & $\mathrm{Fe}, \mathrm{Fe}^{+}, \mathrm{Fe}^{++}$ & 3 \\
\hline$(\mathrm{Ne})$ & $\mathrm{Ne}, \mathrm{Ne}^{+}, \mathrm{Ne}^{++}$ & 3 \\
\hline (Ar) & $\mathrm{Ar}, \mathrm{Ar}^{+}, \mathrm{Ar}^{++}$ & 3 \\
\hline ice & $\mathrm{CO} \#, \mathrm{H}_{2} \mathrm{O} \#, \mathrm{CO}_{2} \#, \mathrm{CH}_{4} \#, \mathrm{NH}_{3} \#, \mathrm{SiO} \#, \mathrm{SO}_{2} \#, \mathrm{O}_{2} \#, \mathrm{HCN} \#, \mathrm{~N}_{2} \#$ & 10 \\
\hline species & total & 100 \\
\hline
\end{tabular}

Notes. Neutral more stable molecules are indicated in bold font and ices are indicated by a trailing \#.

UMIST reference model. However, the effects are very subtle, if the overall gas temperature distribution is considered.

\subsection{The chemical network}

We followed two approaches here: (1) provide a robust and fast standard that enables to deal with simple species (robust tracers) such as $\mathrm{C}, \mathrm{O}, \mathrm{Ne}, \mathrm{CO}, \mathrm{CN}, \mathrm{CO}_{2}, \mathrm{OH}$, and $\mathrm{H}_{2} \mathrm{O}$; (2) provide a consistent standard that can be used as a starting point for further investigation of the chemistry of more complex species such as $\mathrm{HCN}, \mathrm{H}_{2} \mathrm{C}_{2}, \mathrm{HCO}^{+}, \mathrm{N}_{2} \mathrm{H}^{+}$. So far, in the literature no chemistry standard has been defined for disks in the context of multiwavelength fitting of observational data. Instead many different species lists are used and we only start to understand the impact of the species choices and/or presence of ices and electron sinks for the abundance of specific low abundance tracers such as $\mathrm{HCO}^{+}\left(\epsilon \sim 10^{-10}\right)$ (Kamp et al. 2013; Rab et al., in prep.).

Table 3 shows the selection used for many years in the disk modeling for the Herschel open time key program GASPS (Gas Evolution in Planetary Systems, PI: B. Dent); we subsequently refer to this as the small network. The abundances of the robust tracers listed above should be calculated with sufficient accuracy and this will be tested in Sect. 3.6.

Table 4 details the selection of chemical species in the large network. We cover the most important $\mathrm{C} / \mathrm{N} / \mathrm{O}$ chemistry and a simple $\mathrm{S}$ and $\mathrm{Si}$ chemistry. Other elements ( $\mathrm{Na}, \mathrm{Mg}$, $\mathrm{Fe}, \mathrm{Ne}, \mathrm{Ar}$ ) are represented only by their atoms and ions. Detailed PAH charging is used, as well as a large selection of ice species. The selection of species is largely based on the chemical networks of Prasad \& Huntress (1980; C-H, C-C chemistry), van Dishoeck (1990; C-H chemistry) Sternberg \& Dalgarno (1995; Si-chemistry, S-H chemistry, N-chemistry, O-H chemistry), Agúndez et al. (2008; high temperature C-H, C-C chemistry), Hily-Blant et al. (2013; N-chemistry). The size of our network is controlled by a combination of species becoming less reactive or saturated. We apply the following rules to ensure the completeness of the chemical network used:

- Negative ions/molecules have been omitted for the time being except $\mathrm{H}^{-}$.

- We include for all atoms/molecules the positively charged counterpart (for elements also double charged). In some cases $\left(\mathrm{HeH}, \mathrm{HNS}, \mathrm{HSO}, \mathrm{CH}_{3} \mathrm{O}\right.$ ), the neutral one is missing since it is not present/has no reactions in UMIST (e.g., unstable molecule or other reasons).

- $\mathrm{C}-\mathrm{H}$ chemistry processes via $\mathrm{H}_{2}$ addition reactions up to $\mathrm{CH}_{5}^{+}$, which is the maximum hydrogenation possible. $\mathrm{CH}_{5}^{+}$ can then recombine dissociatively to give the closed-shell molecule $\mathrm{CH}_{4}$. We proceed similarly for $\mathrm{Si}-\mathrm{H}$ chemistry, thus stopping at $\mathrm{SiH}_{5}^{+}$, and for $\mathrm{O}-\mathrm{H}$ chemistry, thus stopping at $\mathrm{H}_{3} \mathrm{O}^{+}$.

- We identify the neutral more stable species to be $\mathrm{H}_{2}, \mathrm{CH}_{2}$, $\mathrm{CH}_{4}, \mathrm{C}_{2}, \mathrm{C}_{3}, \mathrm{C}_{4}, \mathrm{C}_{2} \mathrm{H}_{2}$ (acetylene), $\mathrm{C}_{2} \mathrm{H}_{4}$ (ethylene), $\mathrm{C}_{3} \mathrm{H}_{2}$ (cyclopropenylidene), $\mathrm{HCN}$ (hydrogen cyanide), $\mathrm{CO}, \mathrm{CO}_{2}$, $\mathrm{H}_{2} \mathrm{CO}$ (formaldehyde), $\mathrm{CH}_{3} \mathrm{OH}$ (methanol), $\mathrm{CS}$ (carbon monosulfide), $\mathrm{H}_{2} \mathrm{CS}$ (thioformaldehyde), $\mathrm{NH}_{3}$ (ammonia), $\mathrm{NO}_{2}$, HNO (nitroxyl), $\mathrm{N}_{2}, \mathrm{H}_{2} \mathrm{O}, \mathrm{SO}_{2}, \mathrm{H}_{2} \mathrm{~S}$ (hydrogen sulfide), OCS (carbonyl sulfide), $\mathrm{O}_{2}, \mathrm{SiH}_{4}$ (silane), $\mathrm{SiC}$ (silicon carbide), $\mathrm{SiN}$ (silicon nitride), $\mathrm{SiO}$ (silicon monoxide), $\mathrm{SiS}$ (silicon sulfide). For those molecules, we ensure that the respective positive ion and the protonated ion are included. The exception is $\mathrm{HNO}_{2}^{+}$, which is not included in UMIST $\left(\mathrm{HNO}_{2}\right.$ is included as species in UMIST, but has no reactions).

- We decided to keep the isomers $\mathrm{CH}_{3} \mathrm{O}$ and $\mathrm{CH}_{2} \mathrm{OH}$ to study the gas phase formation of methanol. We also keep the isomers $\mathrm{HNC}$ and $\mathrm{HCN}$ since they are both observed. However, we only include the ion $\mathrm{HCN}^{+}$and subsequent hydrogenation.

- We included several species that link the chemical networks with each other, especially for the heavier elements such 
Table 4. Selection of elements and chemical (gas+ice) species in the large network.

\begin{tabular}{|c|c|c|}
\hline 13 elements & $\mathrm{H}, \mathrm{He}, \mathrm{C}, \mathrm{N}, \mathrm{O}, \mathrm{Ne}, \mathrm{Na}, \mathrm{Mg}, \mathrm{Si}, \mathrm{S}, \mathrm{Ar}, \mathrm{Fe}, \mathrm{PAH}$ & \\
\hline$(\mathrm{H})$ & $\mathrm{H}, \mathrm{H}^{+}, \mathrm{H}^{-}, \mathbf{H}_{2}, \mathrm{H}_{2}^{+}, \mathrm{H}_{3}^{+}, \mathrm{H}_{2}^{\mathrm{exc}}$ & 7 \\
\hline$(\mathrm{He})$ & $\mathrm{He}, \mathrm{He}^{+}$ & 2 \\
\hline$(\mathrm{He}-\mathrm{H})$ & $\mathrm{HeH}^{+}$ & 1 \\
\hline$(\mathrm{C}-\mathrm{H})$ & $\mathrm{C}, \mathrm{C}^{+}, \mathrm{C}^{++}, \mathrm{CH}, \mathrm{CH}^{+}, \mathrm{CH}_{2}, \mathrm{CH}_{2}^{+}, \mathrm{CH}_{3}, \mathrm{CH}_{3}^{+}, \mathrm{CH}_{4}, \mathrm{CH}_{4}^{+}, \mathrm{CH}_{5}^{+}$, & 12 \\
\hline \multirow[t]{2}{*}{$(\mathrm{C}-\mathrm{C})$} & $\begin{array}{l}\mathbf{C}_{2}, \mathrm{C}_{2}^{+}, \mathrm{C}_{2} \mathrm{H}, \mathrm{C}_{2} \mathrm{H}^{+}, \mathbf{C}_{2} \mathbf{H}_{2}, \mathrm{C}_{2} \mathrm{H}_{2}^{+}, \mathrm{C}_{2} \mathrm{H}_{3}, \mathrm{C}_{2} \mathrm{H}_{3}^{+}, \mathbf{C}_{2} \mathbf{H}_{4}, \mathrm{C}_{2} \mathrm{H}_{4}^{+}, \mathrm{C}_{2} \mathrm{H}_{5}, \mathrm{C}_{2} \mathrm{H}_{5}^{+}, \\
\mathbf{C}_{3}, \mathrm{C}_{3}^{+}, \mathrm{C}_{3} \mathrm{H}, \mathrm{C}_{3} \mathrm{H}^{+}, \mathbf{C}_{3} \mathbf{H}_{2}, \mathrm{C}_{3} \mathrm{H}_{2}^{+}, \mathrm{C}_{3} \mathrm{H}_{3}^{+},\end{array}$ & \\
\hline & $\mathrm{C}_{4}, \mathrm{C}_{4}^{+}, \mathrm{C}_{4} \mathrm{H}^{+}$ & 23 \\
\hline$(\mathrm{C}-\mathrm{N})$ & $\mathrm{CN}, \mathrm{CN}^{+}, \mathrm{HCN}, \mathrm{HCN}^{+}, \mathrm{HCNH}^{+}, \mathrm{HNC}, \mathrm{H}_{2} \mathrm{CN}, \mathrm{OCN}, \mathrm{OCN}^{+}$ & 9 \\
\hline \multirow[t]{4}{*}{$(\mathrm{C}-\mathrm{O})$} & $\mathbf{C O}, \mathrm{CO}^{+}, \mathrm{HCO}, \mathrm{HCO}^{+}$ & \\
\hline & $\mathbf{C O}_{2}, \mathrm{CO}_{2}^{+}, \mathrm{HCO}_{2}^{+}, \mathrm{C}_{2} \mathrm{O}, \mathrm{C}_{2} \mathrm{O}^{+}, \mathrm{HC}_{2} \mathrm{O}^{+}$ & \\
\hline & $\mathrm{H}_{2} \mathbf{C O}, \mathrm{H}_{2} \mathrm{CO}^{+}, \mathrm{CH}_{3} \mathrm{O}, \mathrm{H}_{3} \mathrm{CO}^{+}, \mathrm{CH}_{2} \mathrm{OH}$ & \\
\hline & $\mathbf{C H}_{3} \mathbf{O H}, \mathrm{CH}_{3} \mathrm{OH}^{+}, \mathrm{CH}_{3} \mathrm{OH}_{2}^{+}$ & 18 \\
\hline \multirow[t]{2}{*}{$(\mathrm{C}-\mathrm{S})$} & $\mathbf{C S}, \mathrm{CS}^{+}, \mathrm{HCS}, \mathrm{HCS}^{+}, \mathbf{H}_{2} \mathbf{C S}, \mathrm{H}_{2} \mathrm{CS}^{+}, \mathrm{H}_{3} \mathrm{CS}^{+}$, & \\
\hline & OCS $, \mathrm{OCS}^{+}, \mathrm{HOCS}^{+}$ & 10 \\
\hline$(\mathrm{N}-\mathrm{H})$ & $\mathrm{N}, \mathrm{N}^{+}, \mathrm{N}^{++}, \mathrm{NH}, \mathrm{NH}^{+}, \mathrm{NH}_{2}, \mathrm{NH}_{2}^{+}, \mathrm{NH}_{3}, \mathrm{NH}_{3}^{+}, \mathrm{NH}_{4}^{+}$, & 10 \\
\hline$(\mathrm{N}-\mathrm{N})$ & $\mathbf{N}_{2}, \mathrm{~N}_{2}^{+}, \mathrm{HN}_{2}^{+}$ & 3 \\
\hline$(\mathrm{N}-\mathrm{O})$ & $\mathrm{NO}, \mathrm{NO}^{+}, \mathrm{NO}_{2}, \mathrm{NO}_{2}^{+}, \mathbf{H N O}, \mathrm{HNO}^{+}, \mathrm{H}_{2} \mathrm{NO}^{+}$ & 7 \\
\hline$(\mathrm{N}-\mathrm{S})$ & $\mathrm{NS}, \mathrm{NS}^{+}, \mathrm{HNS}^{+}$ & 3 \\
\hline$(\mathrm{O}-\mathrm{H})$ & $\mathrm{O}, \mathrm{O}^{+}, \mathrm{O}^{++}, \mathrm{OH}, \mathrm{OH}^{+}, \mathbf{H}_{2} \mathbf{O}, \mathrm{H}_{2} \mathrm{O}^{+}, \mathrm{H}_{3} \mathrm{O}^{+}$, & 8 \\
\hline$(\mathrm{O}-\mathrm{O})$ & $\mathbf{O}_{2}, \mathrm{O}_{2}^{+}, \mathrm{O}_{2} \mathrm{H}^{+}$ & 3 \\
\hline$(\mathrm{O}-\mathrm{S})$ & $\mathrm{SO}, \mathrm{SO}^{+}, \mathrm{SO}_{2}, \mathrm{SO}_{2}^{+}, \mathrm{HSO}_{2}^{+}$, & 5 \\
\hline$(\mathrm{S}-\mathrm{H})$ & $\mathrm{S}, \mathrm{S}^{+}, \mathrm{S}^{++}, \mathrm{HS}, \mathrm{HS}^{+}, \mathbf{H}_{2} \mathrm{~S}, \mathrm{H}_{2} \mathrm{~S}^{+}, \mathrm{H}_{3} \mathrm{~S}^{+}$ & 8 \\
\hline$(\mathrm{Si}-\mathrm{H})$ & $\mathrm{Si}, \mathrm{Si}^{+}, \mathrm{Si}^{++}, \mathrm{SiH}, \mathrm{SiH}^{+}, \mathrm{SiH}_{2}, \mathrm{SiH}_{2}^{+}, \mathrm{SiH}_{3}, \mathrm{SiH}_{3}^{+}, \mathrm{SiH}_{4}, \mathrm{SiH}_{4}^{+}, \mathrm{SiH}_{5}^{+}$, & 12 \\
\hline$(\mathrm{Si}-\mathrm{C})$ & $\mathrm{SiC}, \mathrm{SiC}^{+}, \mathrm{HCSi}^{+}$ & 3 \\
\hline$(\mathrm{Si}-\mathrm{N})$ & $\mathrm{SiN}, \mathrm{SiN}^{+}, \mathrm{HNSi}^{+}$, & 3 \\
\hline$(\mathrm{Si}-\mathrm{O})$ & $\mathrm{SiO}, \mathrm{SiO}^{+}, \mathrm{SiOH}^{+}$ & 3 \\
\hline$(\mathrm{Si}-\mathrm{S})$ & $\mathrm{SiS}, \mathrm{SiS}^{+}, \mathrm{HSiS}^{+}$ & 3 \\
\hline$(\mathrm{Na})$ & $\mathrm{Na}, \mathrm{Na}^{+}, \mathrm{Na}^{++}$ & 3 \\
\hline$(\mathrm{Mg})$ & $\mathrm{Mg}, \mathrm{Mg}^{+}, \mathrm{Mg}^{++}$ & 3 \\
\hline$(\mathrm{Fe})$ & $\mathrm{Fe}, \mathrm{Fe}^{+}, \mathrm{Fe}^{++}$ & 3 \\
\hline$(\mathrm{Ne})$ & $\mathrm{Ne}, \mathrm{Ne}^{+}, \mathrm{Ne}^{++}$ & 3 \\
\hline (Ar) & $\mathrm{Ar}, \mathrm{Ar}^{+}, \mathrm{Ar}^{++}$ & 3 \\
\hline (PAH) & PAH-, $\mathrm{PAH}, \mathrm{PAH}^{+}, \mathrm{PAH}^{++}, \mathrm{PAH}^{+++}$, & 5 \\
\hline ice & all neutral gas species except noble gases have ice counterparts & 64 \\
\hline species & total & 235 \\
\hline
\end{tabular}

Notes. Neutral more stable molecules are indicated in bold font.

as $\mathrm{S}, \mathrm{N}$, and $\mathrm{Si}$. An interesting example is the radical $\mathrm{H}_{2} \mathrm{CN}$ (amidogen). It is formed by collisions between $\mathrm{N}$ and $\mathrm{C}-\mathrm{H}$ chains and forms a $\mathrm{CN}$ bond. This connects the $\mathrm{C}-\mathrm{H}, \mathrm{C}-\mathrm{C}$ chemistry with the nitrogen chemistry.

- Neutral atoms/molecules (including radicals) except noble gases can freeze out.

\subsection{Reaction rates}

ProDiMo selects from the UMIST2012 database all reactions among the species defined in the chemical network above. However, in some cases, we add additional reactions and/or overwrite UMIST reactions following the procedures described in Appendices A.1-A.7. Alternatively, we also use the UMIST2006, the OSU and the KIDA 2011 databases.

\subsection{Element abundances}

Table 5 describes the selection of elements and their respective abundances. These are very similar to the low-metal abundances used in the literature for example those of Lee et al. (1998). All following models adopt these low metal abundances.
Table 5. Elements, their abundances on the scale $\log n_{\mathrm{H}}=12$ and their masses in amu.

\begin{tabular}{crr|crr}
\hline \hline Element & $12+\log \epsilon$ & $m[\mathrm{amu}]$ & Element & $12+\log \epsilon$ & $m[\mathrm{amu}]$ \\
\hline $\mathrm{H}$ & 12.00 & 1.0079 & $\mathrm{Na}$ & 3.36 & 22.990 \\
$\mathrm{He}$ & 10.98 & 4.0026 & $\mathrm{Mg}$ & 4.03 & 24.305 \\
$\mathrm{C}$ & 8.14 & 12.011 & $\mathrm{Si}$ & 4.24 & 28.086 \\
$\mathrm{~N}$ & 7.90 & 14.007 & $\mathrm{~S}$ & 5.27 & 32.066 \\
$\mathrm{O}$ & 8.48 & 15.999 & $\mathrm{Ar}$ & 6.08 & 39.948 \\
$\mathrm{Ne}$ & 7.95 & 20.180 & $\mathrm{Fe}$ & 3.24 & 55.845 \\
\hline
\end{tabular}

\subsection{The line list}

Table 6 describes the list of lines used to analize how changes in disk chemistry propagate into observable line fluxes. The atomic and molecular data is collected from LAMDA (Schöier et al. 2005), NIST and CHIANTI (Dere et al. 1997). Line fluxes are calculated using level populations from statistical equilibrium and a simplified 2D escape probability approach. Detailed radiative transfer tests show that line fluxes from escape probability are typically off by less than $50 \%$ except for close to edge on disk geometries and/or lines where a significant fraction of total emission originates from the inner rim (e.g., Woitke et al. 2009b; Antonellini et al. 2015). 
I. Kamp et al.: Consistent dust and gas models for protoplanetary disks. II.

Table 6. Lines used to analize flux changes related to chemistry.

\begin{tabular}{|c|c|c|c|c|}
\hline Species & Designation & $E_{\text {up }}[\mathrm{K}]$ & $A_{i j}\left[\mathrm{~s}^{-1}\right]$ & $\lambda[\mu \mathrm{m}]$ \\
\hline $\mathrm{CO}$ & $J=2-1$ & 16.60 & $6.910(-7)$ & 1300.40 \\
\hline${ }^{13} \mathrm{CO}$ & $J=2-1$ & 15.87 & $6.038(-7)$ & 1360.23 \\
\hline $\mathrm{C}^{18} \mathrm{O}$ & $J=2-1$ & 15.81 & $6.011(-7)$ & 1365.42 \\
\hline $\mathrm{CO}$ & $J=3-2$ & 33.19 & $2.497(-6)$ & 866.96 \\
\hline${ }^{13} \mathrm{CO}$ & $J=3-2$ & 31.73 & $2.181(-6)$ & 906.84 \\
\hline $\mathrm{C}^{18} \mathrm{O}$ & $J=3-2$ & 31.61 & $2.172(-6)$ & 910.31 \\
\hline $\mathrm{CO}$ & $J=18-17$ & 944.97 & $5.695(-4)$ & 144.78 \\
\hline $\mathrm{CO}$ & $J=36-35$ & 3668.78 & $3.638(-3)$ & 72.84 \\
\hline $\mathrm{CO}$ & $v=1-0 J=3-4$ & 3116.70 & $1.950(1)$ & 4.699950 \\
\hline $\mathrm{CO}$ & $v=1-0 \mathrm{~J}$ & 6523.52 & $1.407(1)$ & 5.040484 \\
\hline $\mathrm{CO}$ & $v=2-1 J$ & 6162.10 & $3.745(1)$ & 4.758863 \\
\hline OI & ${ }^{3} \mathrm{P}_{1}-{ }^{3} \mathrm{P}_{2}$ & 227.712 & $8.91(-5)$ & 63.18 \\
\hline OI & ${ }^{3} \mathrm{P}_{0}-{ }^{3} \mathrm{P}_{1}$ & 326.579 & $1.750(-5)$ & 145.53 \\
\hline OI & ${ }^{1} \mathrm{D}_{2}-{ }^{3} \mathrm{P}_{2}$ & 22830.18 & $6.535(-3)$ & 0.63003 \\
\hline CII & ${ }^{2} \mathrm{P}_{3 / 2}-{ }^{2} \mathrm{P}_{1 / 2}$ & 91.21 & $2.300(-6)$ & 157.74 \\
\hline CI & ${ }^{3} \mathrm{P}_{1}-{ }^{3} \mathrm{P}_{0}$ & 23.620 & $7.880(-8)$ & 609.14 \\
\hline $\mathrm{CI}$ & ${ }^{3} \mathrm{P}_{2}-{ }^{3} \mathrm{P}_{1}$ & 62.462 & $2.650(-7)$ & 370.42 \\
\hline $\mathrm{NeII}$ & ${ }^{2} \mathrm{P}_{1 / 2}-{ }^{3} \mathrm{P}_{3 / 2}$ & 1122 & $8.59(-3)$ & 12.815 \\
\hline $\mathrm{NeIII}$ & ${ }^{3} \mathrm{P}_{1}-{ }^{3} \mathrm{P}_{2}$ & 924.98 & $5.97(-3)$ & 15.555 \\
\hline SII & ${ }^{2} D_{5 / 2}{ }^{4} S_{3 / 2}$ & 21420 & $3.338(-4)$ & 0.67164 \\
\hline SIII & ${ }^{3} \mathrm{P}_{2}-{ }^{3} \mathrm{P}_{1}$ & 1199.904 & $2.07(-3)$ & 18.716 \\
\hline ArII & ${ }^{2} \mathrm{P}_{1 / 2}-{ }^{2} \mathrm{P}_{3 / 2}$ & 2059.72 & $5.3(-2)$ & 6.985 \\
\hline ArIII & ${ }^{3} \mathrm{P}_{0}-{ }^{3} \mathrm{P}_{1}$ & 2259.2 & $5.19(-3)$ & 21.816 \\
\hline FeII & ${ }^{6} \mathrm{D}_{9 / 2}{ }^{6} \mathrm{D}_{7 / 2}$ & 553.6 & $2.13(-3)$ & 25.988 \\
\hline SiII & ${ }^{2} \mathrm{P}_{1 / 2}-{ }^{2} \mathrm{P}_{3 / 2}$ & 413.21 & $2.132(-4)$ & 34.807 \\
\hline $\mathrm{OH}$ & ${ }^{2} \Pi_{1 / 2} 7 / 2^{+}-5 / 2^{-}$ & 617.9 & 1.012 & 71.22 \\
\hline $\mathrm{OH}$ & ${ }^{2} \Pi_{1 / 2} 7 / 2^{-}-5 / 2^{+}$ & 617.6 & 1.014 & 71.17 \\
\hline $\mathrm{OH}$ & ${ }^{2} \Pi_{1 / 2} 1 / 2^{-}-{ }^{2} \Pi_{3 / 2} 3 / 2^{+}$ & 181.9 & $3.606(-2)$ & 79.11 \\
\hline $\mathrm{OH}$ & ${ }^{2} \Pi_{1 / 2} 1 / 2^{+}-{ }^{2} \Pi_{3 / 2} 3 / 2^{-}$ & 181.7 & $3.598(-2)$ & 79.18 \\
\hline $\mathrm{OH}$ & ${ }^{2} \Pi_{3 / 2} 5 / 2^{-}-3 / 2^{+}$ & 120.7 & $1.388(-1)$ & 119.23 \\
\hline $\mathrm{OH}$ & ${ }^{2} \Pi_{3 / 2} 5 / 2^{+}-3 / 2^{-}$ & 120.5 & $1.380(-1)$ & 119.44 \\
\hline $\mathrm{o}-\mathrm{H}_{2} \mathrm{O}$ & $1_{10}-1_{01}$ & 61.0 & $3.458(-3)$ & 538.29 \\
\hline $\mathrm{o}-\mathrm{H}_{2} \mathrm{O}$ & $2_{12}-1_{01}$ & 114.4 & $5.593(-2)$ & 179.53 \\
\hline $\mathrm{o}-\mathrm{H}_{2} \mathrm{O}$ & $4_{23}-3_{12}$ & 432.2 & $4.838(-1)$ & 78.74 \\
\hline $\mathrm{o}-\mathrm{H}_{2} \mathrm{O}$ & $8_{18}-7_{07}$ & 1070.7 & 1.751 & 63.32 \\
\hline $\mathrm{p}-\mathrm{H}_{2} \mathrm{O}$ & $1_{11}-0_{00}$ & 53.4 & $1.842(-2)$ & 269.27 \\
\hline $\mathrm{p}-\mathrm{H}_{2} \mathrm{O}$ & $4_{13}-4_{04}$ & 396.4 & $3.726(-2)$ & 187.110 \\
\hline $\mathrm{p}-\mathrm{H}_{2} \mathrm{O}$ & $3_{22}-2_{11}$ & 296.8 & $3.524(-1)$ & 89.988 \\
\hline $\mathrm{o}-\mathrm{H}_{2}$ & $v=0-0 \mathrm{~S}(1) J=?$ & 1015 & $4.76(-10)$ & 17.034 \\
\hline $\mathrm{p}-\mathrm{H}_{2}$ & $v=0-0 \mathrm{~S}(2) J=4-2$ & 1682 & $2.754(-9)$ & 12.278 \\
\hline $\mathrm{p}-\mathrm{H}_{2}$ & $v=0-0 \mathrm{~S}(4) J=6-4$ & 3474 & $2.642(-8)$ & 8.025 \\
\hline $\mathrm{o}-\mathrm{H}_{2}$ & $v=0-0 \mathrm{~S}(9) J=11-9$ & 10262 & $4.898(-7)$ & 4.694 \\
\hline $\mathrm{o}-\mathrm{H}_{2}$ & $v=2-1 \mathrm{~S}(1) J=3-1$ & 12550 & $4.977(-7)$ & 2.248 \\
\hline $\mathrm{p}-\mathrm{H}_{2}$ & $v=1-0 \mathrm{~S}(0) J=2-0$ & 6472 & $2.526(-7)$ & 2.223 \\
\hline $\mathrm{o}-\mathrm{H}_{2}$ & $v=1-0 \mathrm{~S}(1) J=3-1$ & 6952 & $3.471(-7)$ & 2.122 \\
\hline $\mathrm{CN}$ & $N=2-1 J=5 / 2-3 / 2$ & 16.34 & $1.143(-4)$ & 1321.380 \\
\hline $\mathrm{CN}$ & $N=5-4 J=11 / 2-9 / 2$ & 81.64 & $2.027(-3)$ & 528.78 \\
\hline $\mathrm{HCN}$ & $J=3-2$ & 25.52 & $8.3559(-4)$ & 1127.521 \\
\hline $\mathrm{HCN}$ & $J=4-3$ & 42.53 & $2.054(-3)$ & 845.66 \\
\hline $\mathrm{CH}^{+}$ & $J=2-1$ & 120.195 & $4.760(-2)$ & 179.594 \\
\hline $\mathrm{CH}^{+}$ & $J=4-3$ & 400.086 & 0.3781 & 90.011 \\
\hline $\mathrm{CH}^{+}$ & $J=5-4$ & 599.524 & 0.7346 & 72.137 \\
\hline $\mathrm{HCO}^{+}$ & $J=1-0$ & 4.28 & $4.2512(-5)$ & 3361.334 \\
\hline $\mathrm{HCO}^{+}$ & $J=3-2$ & 25.68 & $1.4757(-3)$ & 1120.478 \\
\hline $\mathrm{HCO}^{+}$ & $J=4-3$ & 42.80 & $3.6269(-3)$ & 840.380 \\
\hline $\mathrm{N}_{2} \mathrm{H}^{+}$ & $J=3-2$ & 26.83 & $1.2586(-3)$ & 1072.558 \\
\hline
\end{tabular}

Notes. The notation $x(-y)$ stands for $x 10^{-y}$.

Details on collision cross sections and collision partners can be found in a series of papers: atoms, ions and $\mathrm{H}_{2}$ (Woitke et al. 2009a), $\mathrm{CH}^{+}$(Thi et al. 2011a), double-ionized species (Aresu et al. 2012), $\mathrm{CO}$ (Thi et al. 2013), $\mathrm{H}_{2} \mathrm{O}$ (Kamp et al. 2013). The collision data for the remaining molecules is taken from the LAMDA database. The $\mathrm{CN}$ collision partners are $\mathrm{He}$ and e; the $\mathrm{HCO}^{+}$collision partner is $\mathrm{H}_{2}$; the $\mathrm{HCN}$ collision partners are $\mathrm{H}_{2}$, He and e; the $\mathrm{OH}$ collision partners are orthoand para- $\mathrm{H}_{2}$.

\section{Results}

\subsection{The base model}

The physical properties of the reference model are described in detail in Woitke et al. (2016) and we summarize here a few key features relevant for the chemical studies. The model reaches total hydrogen number densities of $10^{14}-10^{16} \mathrm{~cm}^{3}$ in the midplane inside $1 \mathrm{au}$. The dust temperature decreases from $\sim 1500 \mathrm{~K}$ at the inner rim to $100 \mathrm{~K}$ at $\sim 1$ au. Gas and dust are thermally well coupled below $A_{\mathrm{V}} \sim 1$ (toward the disk midplane). At the disk surface above $A_{\mathrm{V}}=1$, the gas temperature reaches values up to several $1000 \mathrm{~K}$. Only in the outer disk atmosphere beyond $100 \mathrm{au}$ and below $z / r=0.4$ (corresponding to $\sim 20^{\circ}$ opening angle), the gas temperature drops below that of the dust.

The abundance distribution - using the small network - for the key species $\mathrm{CO}, \mathrm{CO} \#, \mathrm{CO}_{2}, \mathrm{CO}_{2} \#, \mathrm{HCO}^{+}, \mathrm{OH}, \mathrm{H}_{2} \mathrm{O} \#, \mathrm{CN}$, $\mathrm{HCN}, \mathrm{HCN} \#, \mathrm{NH}_{3}, \mathrm{NH}_{3} \#$ is shown in Fig. 1 for the reference model (model1; note that the trailing \# denotes the ice form of this species). The CO surface is reasonably well described using the PDR parameter $\log \chi /\left\langle n_{\mathrm{H}}\right\rangle$. For values larger than -3.5 , $\mathrm{CO}$ is efficiently photo dissociated ${ }^{1}$ and has abundances below $\log n_{\mathrm{CO}} /\left\langle n_{\mathrm{H}}\right\rangle=\log \epsilon_{\mathrm{CO}}=-8$. Here, $\left\langle n_{\mathrm{H}}\right\rangle$ is the total hydrogen number density. The $\mathrm{CO}$ ice line is reasonably well described by the $T_{\text {dust }}=20 \mathrm{~K}$ line, but a rate equilibrium approach works even better (Antonellini 2016, white dashed line). The disk shows a ring of high $\mathrm{CO}_{2}$ abundance inside 1 au. The $\mathrm{CO}_{2}$ ice is sandwiched between the water and $\mathrm{CO}$ ice reservoirs. $\mathrm{HCO}^{+}$only resides in a very thin layer below the $\mathrm{C}^{+} / \mathrm{C} / \mathrm{CO}$ transition when the small chemical network is used.

The $\mathrm{OH}$ molecule constitutes the first step in the neutralneutral chemical pathway to water formation. It is concentrated in the surface layers of the inner disk $(r<10 \mathrm{au})$ where gas temperatures are between 200 and $2000 \mathrm{~K}$. Just below the OH reservoir, inside $0.5 \mathrm{au}$, densities are high enough to efficiently form water with an abundance of $10^{-4}$. Beyond the snow line, water freezes out onto the cold dust grains. The water ice reservoir is outlined well by a rate equilibrium approach (Antonellini 2016, yellow dashed line) or using the water vapor pressure together with the local radiation field (Min et al. 2016a, white dashed line).

The disk model contains only minute amounts of $\mathrm{CN}$ in the disk atmosphere $\left(\log \epsilon_{\mathrm{CN}}<-8\right)$. Instead we identify two large $\mathrm{HCN}$ reservoirs with $\log \epsilon_{\mathrm{HCN}} \sim-4$, a narrow ring around $0.2 \mathrm{au}$ and a broader ring between 1 and 5 au. These two reservoirs sit below the $A_{\mathrm{V}}=1$ surface where $T_{\text {gas }}=T_{\text {dust }}$. An additional lower abundance reservoir $\left(\log \epsilon_{\mathrm{HCN}} \sim-8\right)$ can be found in the outer disk atmosphere beyond $100 \mathrm{au}$. The most stable nitrogen bearing molecule, $\mathrm{NH}_{3}$ is only found in a very narrow ring close to the inner rim of the disk. In this particular model, $\mathrm{NH}_{3}$ ice plays a minor role as a nitrogen reservoir.

Some of these results will depend on the details of the chosen disk model, on the set of adsorption energies used and also on the size of the chemical network. The impact of the latter two will be discussed in the subsequent sections.

1 Self-shielding is taken into account using the approach described in Woitke et al. (2009a). 

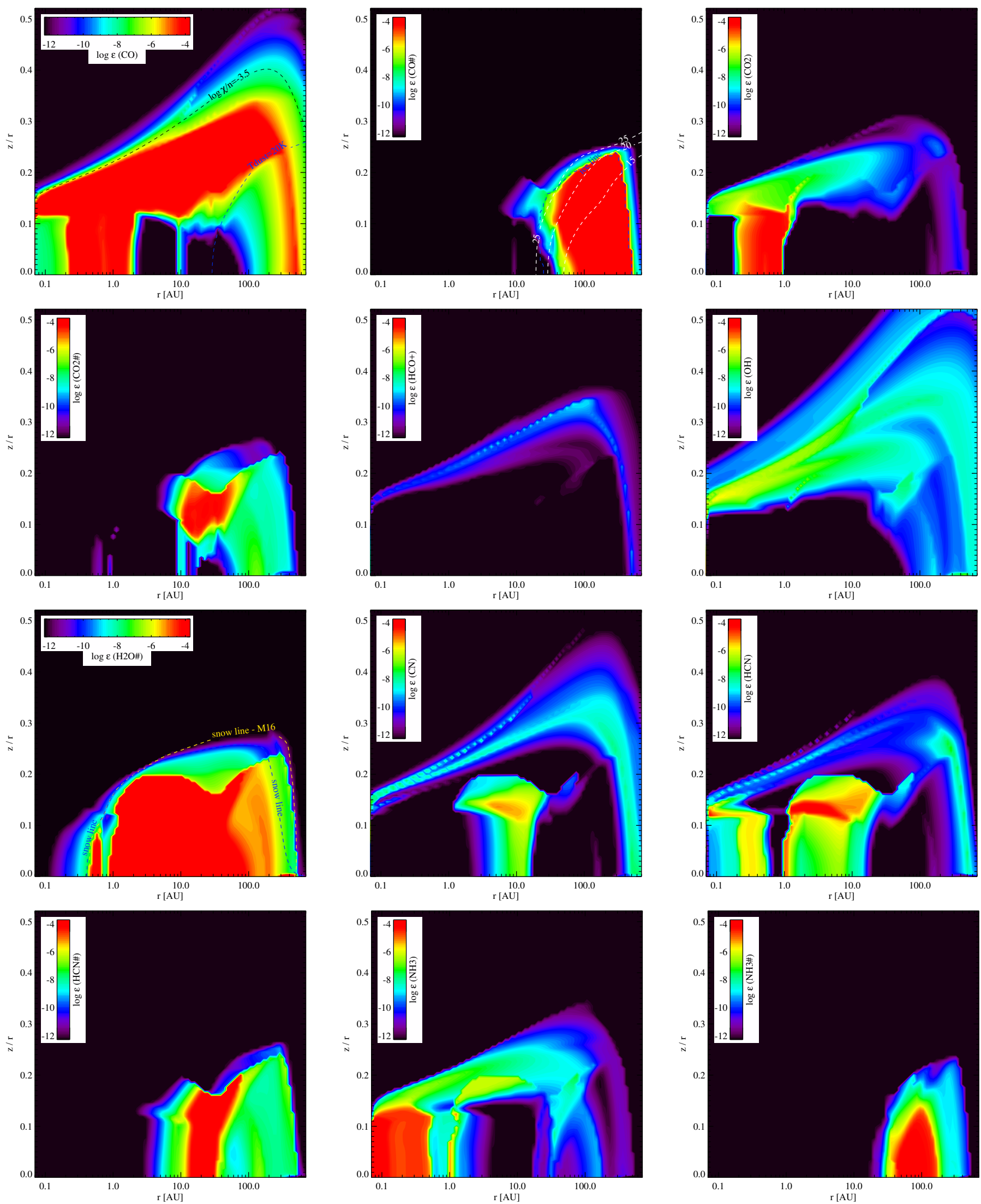

Fig. 1. Distribution of key species abundances in the base model: $\mathrm{CO}, \mathrm{CO} \#, \mathrm{CO}_{2}, \mathrm{CO}_{2} \#, \mathrm{HCO}^{+}, \mathrm{OH}, \mathrm{H}_{2} \mathrm{O} \#, \mathrm{CN}, \mathrm{HCN}, \mathrm{HCN \#}, \mathrm{NH}$, $\mathrm{NH}$ \#. For $\mathrm{CO}$, the black contour shows the PDR parameter $\log \chi /\left\langle n_{\mathrm{H}}\right\rangle=-3.5$ and the blue contour $T_{\text {dust }}=20 \mathrm{~K}$ where CO starts to freeze out on dust grains. For CO\#, the white dashed contours show dust temperatures of 15, 20 and $25 \mathrm{~K}$ and the blue dashed line shows the CO ice line estimate from rate equilibrium (Antonellini 2016). For water ice, two approximations of the snow line are indicated: (1) estimate based on the local density, dust temperature and radiation field (Min et al. 2016a, yellow dashed) and (2) estimate from rate equilibrium (Antonellini 2016, blue dashed). 
I. Kamp et al.: Consistent dust and gas models for protoplanetary disks. II.

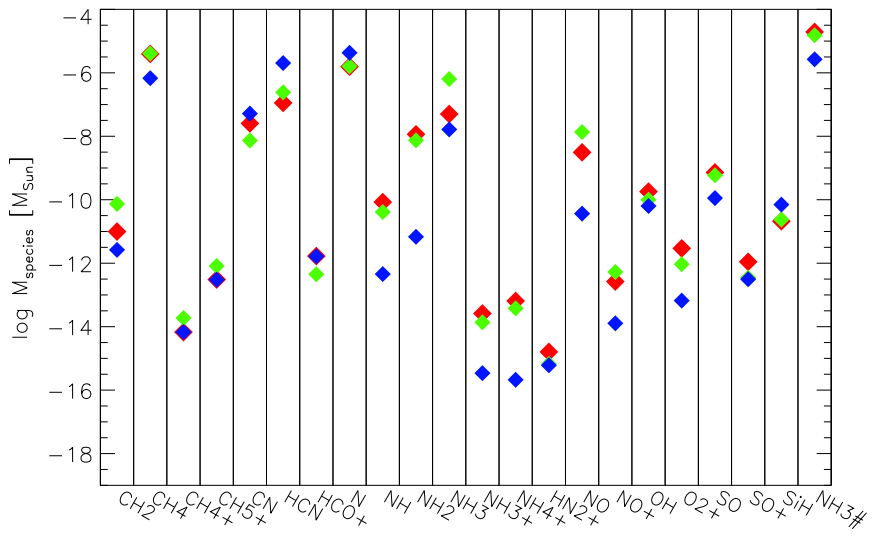

Fig. 2. Differences in species masses between three different sets of reactions: UMIST2012 plus collider reactions from UMIST2006 (red, model 1), UMIST2006 (green, model 2) and UMIST2012 (blue, model 1a).

\subsection{Chemical rates from UMIST2006 to 2012}

The revision of the UMIST database in 2012 reveals major differences in species masses especially for nitrogen bearing species. The main reason is the missing collider reactions with respect to the UMIST2006 rate file. Figure 2 shows this effect for the species that change by more than a factor three and have absolute masses above $10^{-15} M_{\odot}$. Species not shown here vary by less than a factor three.

In the case of UMIST2012 without the collider reactions, water and $\mathrm{OH}$ abundances in the surface of the outer disk change by orders of magnitude; in fact, the entire water vapor reservoir on top of the water ice reservoir disappears (Fig. 3). This is also reflected in the water and $\mathrm{OH}$ line fluxes changing by a factor $3-$ 10 (Fig. 4). The rates were not deliberately omitted, but simply not re-assessed in UMIST2012, hence the UMIST2006 collider reactions should be used (Millar, priv. comm.). Adding the collider reactions brings back the water and $\mathrm{OH}$ reservoir and also leads to a match of the water and $\mathrm{OH}$ line fluxes to within a factor of 2-3 (Fig. 5). The three-body (collider) reaction opening the water formation pathway is

$\mathrm{N}+\mathrm{H}_{2}+\mathrm{M} \rightarrow \mathrm{NH}_{2}$,

with a reaction rate of $10^{-26} \mathrm{~cm}^{6} \mathrm{~s}^{-1}$ (Avramenko \& Krasnenkov 1966). The rate is constant over the temperature range 564-796 K according to NIST. Since we extrapolate rates outside the temperature range, it gets applied also in the somewhat cooler disk surface regions $(20-300 \mathrm{~K})$. This rate stems from a very old measurement and definitely needs to be revisited. $\mathrm{NH}_{2}$ subsequently reacts with oxygen to form $\mathrm{NH}$ and $\mathrm{OH}$. Both radicals react further to form water (Kamp et al. 2013). The more classical neutral-neutral pathway identified for example by Glassgold et al. (2009)

$\mathrm{O} \stackrel{\mathrm{H}_{2}}{\longrightarrow} \mathrm{OH} \longrightarrow \mathrm{H}_{2} \mathrm{H}_{2} \mathrm{O}$

acts at higher gas temperatures $\left(T_{\text {gas }} \gg 200 \mathrm{~K}\right)$ closer to the star.

$\mathrm{CN}, \mathrm{OH}$ and $\mathrm{HCO}^{+}$show differences in species mass of up to 0.5 dex between UMIST2006 and UMIST2012 (plus collider reactions). Lines of these species are frequently observed in the far-IR and submm wavelength range and their predicted line fluxes can differ by up to a factor 2.5 for $\mathrm{CN}$ and $\mathrm{OH}$ and up to a factor six for $\mathrm{HCO}^{+}$, with UMIST2012 giving systematically higher fluxes (Fig. 5). Throughout the remainder of this paper, we use "UMIST2012" as a replacement for "UMIST2012 rate database including the collider reactions".
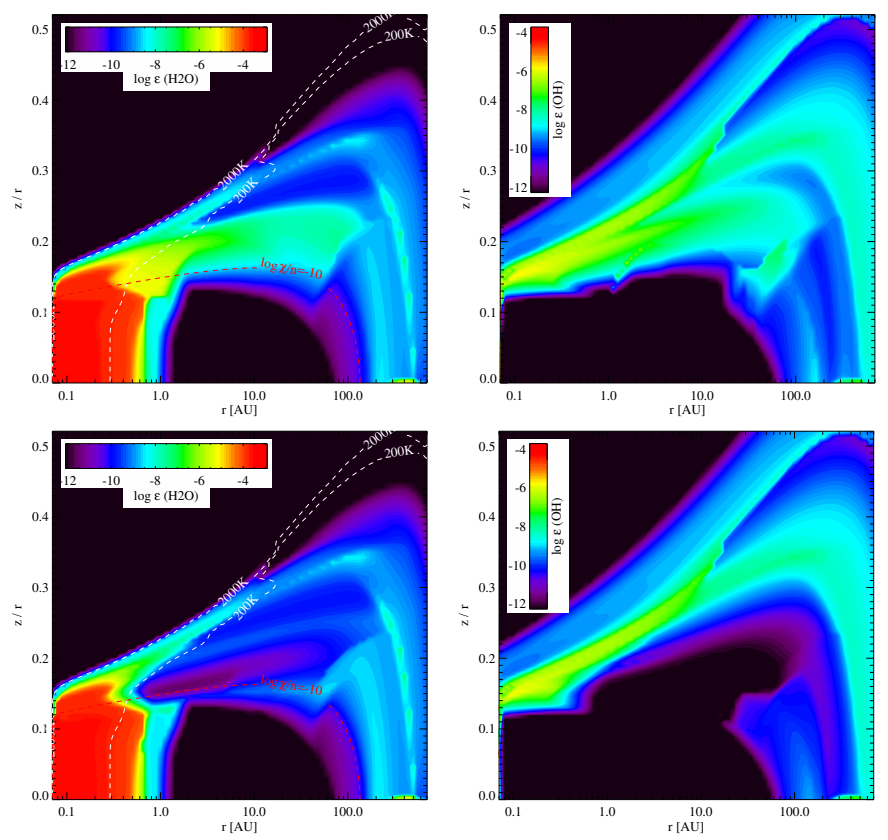

Fig. 3. Comparison of water and $\mathrm{OH}$ abundances in the UMIST2012 model with (top, model 1) and without collider reactions (bottom, model 1a).

\subsection{Chemical reaction databases}

We test the impact of different sets of reaction rates on the overall disk chemistry and appearance. Three databases are investigated: UMIST2012 (model 1), OSU (model 3) and KIDA (model 4). In all cases, we use the small chemical network and the adsorption energies of Aikawa et al. (1996). We also keep the physical and thermal structure of the underlying disk constant.

Given that these databases have been compiled with different focus, it is not surprizing that almost one third of the species masses change by more than 0.5 dex. In addition, collider reactions are not a priori included in these databases; hence water and $\mathrm{OH}$ are affected in the same way as described in Sect. 3.2. Figure 6 provides an overview of a few key species for OSU and KIDA and can be compared to Figs. 1 and 3.

However, despite these large changes in the overall chemical structure, some line tracers stay very robust while others change by more than 1 dex (see Figs. 7 and 8):

- The low excitation CO lines hardly change. This is due to the simple molecular cloud like chemistry in the outer disk. However, there are significant changes in the high excitation rotational lines and ro-vibrational lines that originate in the inner 10 au where CO chemistry is driven by ionmolecule and in lower layers by neutral-neutral reactions. Interestingly, OSU gives systematically higher fluxes, while KIDA is lower than UMIST2012. This relates to the depth at which the $\mathrm{C}^{+} / \mathrm{C} / \mathrm{CO}$ transition is reached in those different networks. Self-shielding is treated in the same way for all three networks. The main $\mathrm{CO}$ formation reactions are via $\mathrm{OH}$ producing $\mathrm{CO}^{+}$. The $\mathrm{OH}$ radical can react with $\mathrm{H}_{2}, \mathrm{~N}$ or $\mathrm{C}^{+}$and the latter forms $\mathrm{CO}^{+}\left(\mathrm{OH}+\mathrm{C}^{+} \rightarrow \mathrm{CO}^{+}+\mathrm{H}\right)$. Subsequent reactions with $\mathrm{H}$ and $\mathrm{H}_{2}$ lead to $\mathrm{CO}\left(\mathrm{CO}^{+}+\mathrm{H} \rightarrow\right.$ $\mathrm{CO}+\mathrm{H}^{+}$and $\mathrm{CO}^{+}+\mathrm{H}_{2} \rightarrow \mathrm{HCO}^{+}+\mathrm{H}$ followed by $\mathrm{HCO}^{+}+$ $\mathrm{e} \rightarrow \mathrm{CO}+\mathrm{H})$. Reaction rates for these differ between the networks. Apparently, even small rate differences can lead to significant differences in line fluxes. The transition lies 

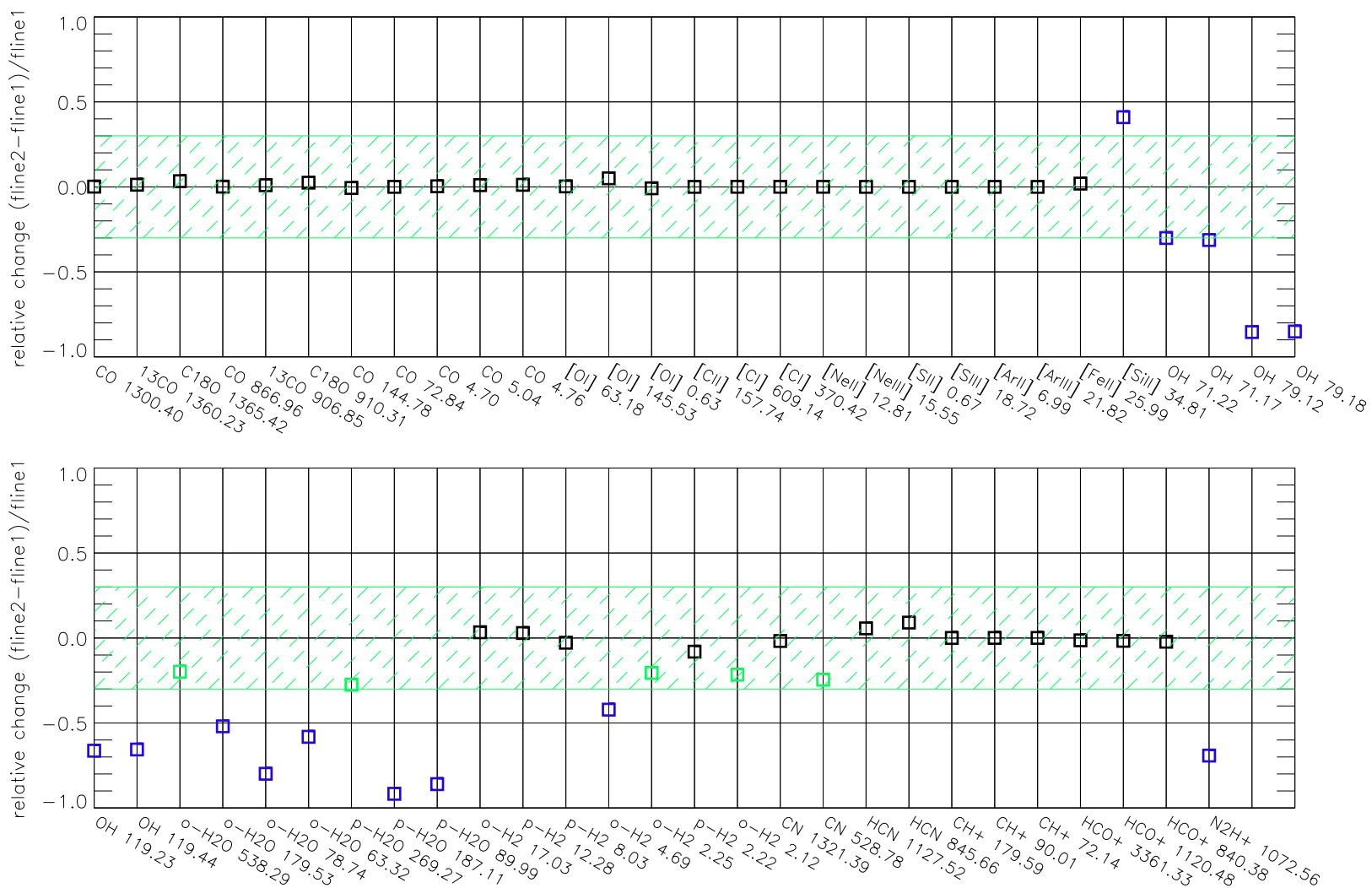

Fig. 4. Comparison of line fluxes for two sets of reactions: UMIST2012 plus CL reactions from UMIST2006 (fline1, model 1) and UMIST2012 (fline2, model 1a). Black and green squares denote differences of less than $25 \%$ and less than a factor two respectively, blue squares and red triangles denote differences larger than a factor three and ten respectively.
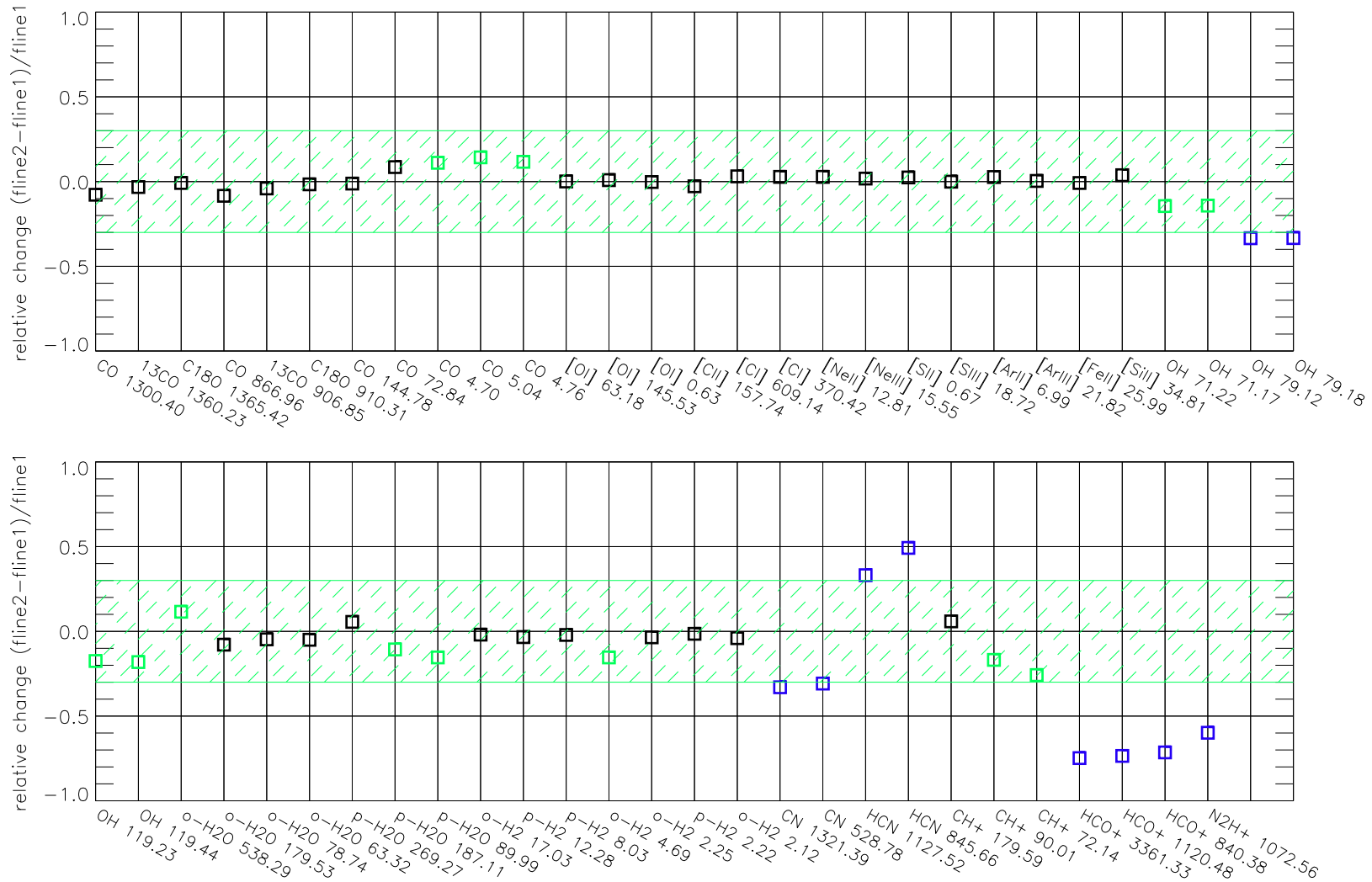

Fig. 5. Comparison of line fluxes for two sets of reactions: UMIST2012 plus CL reactions from UMIST2006 (fline1, model 1) and UMIST2006 (fline2, model 2). Black and green squares denote differences of less than $25 \%$ and less than a factor two respectively, blue squares and red triangles denote differences larger than a factor three and ten respectively. 
I. Kamp et al.: Consistent dust and gas models for protoplanetary disks. II.
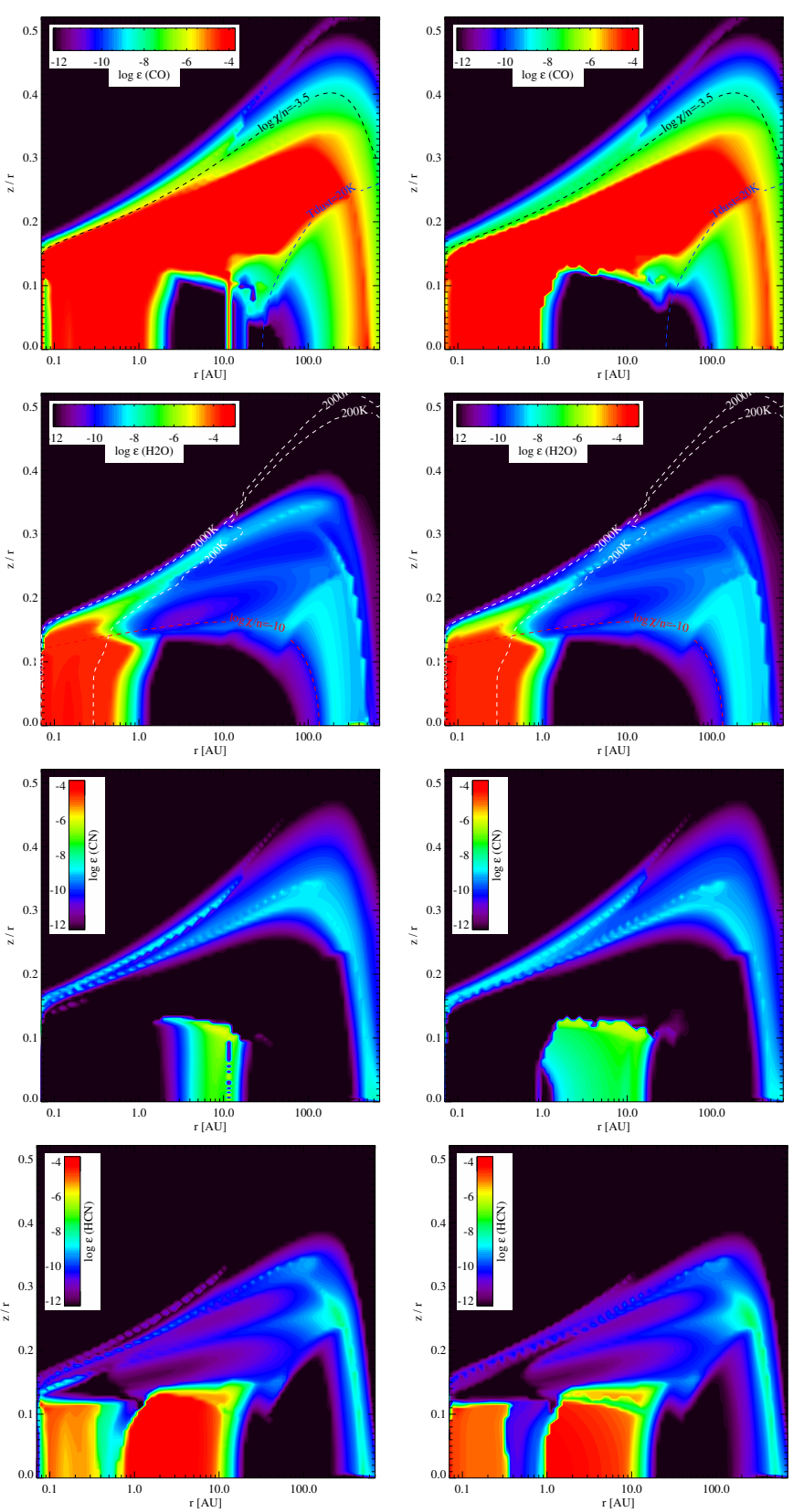

Fig. 6. Distribution of key species abundances using OSU (left) and KIDA (right): $\mathrm{CO}, \mathrm{H}_{2} \mathrm{O}, \mathrm{CN}, \mathrm{HCN}$. Contours are the same as those in Figs. 1 and 3.

closest to the surface in the OSU model, while it lies deepest in the KIDA model (see Figs. 1 and 6); note that the CO high excitation lines react very strongly to changes in temperature and the $\mathrm{C}^{+} / \mathrm{C} / \mathrm{CO}$ transition has a steep vertical temperature gradient.

- The neutral and ionized atomic line fluxes are very robust and stay within a factor two across all networks; those species are dominated by photochemistry and their abundance (and line flux) directly reflects the choice of elemental abundances.

- $\mathrm{H}_{2}$ chemistry is driven by formation on dust and photodissociation; these processes are implemented outside the specific network. A crucial reaction in the inner disk destroying $\mathrm{H}_{2}$ is collisions with atomic oxygen, leading to the formation
Table 7. Comparison of rate coefficients for $\mathrm{CH}^{+}$formation and destruction reactions.

\begin{tabular}{l|rrr|rrr}
\hline \hline Reaction & \multicolumn{3}{|c|}{ KIDA 2011 } & \multicolumn{3}{|c}{ UMIST 2012 } \\
& $A$ & $B$ & $C$ & $A$ & $B$ & $C$ \\
\hline $\mathrm{C}+\mathrm{H}_{3}^{+}$ & $2(-9)$ & 0.0 & 0.0 & $2.00(-9)$ & 0.0 & 0.0 \\
$\mathrm{C}^{+}+\mathrm{H}_{2}$ & $7.8(-10)$ & 0.0 & 4540.0 & $1.00(-10)$ & 0.0 & 4640.0 \\
$\mathrm{CH}^{+}+\mathrm{H}_{2}$ & $1.20(-9)$ & 0.0 & 0.0 & $1.20(-9)$ & 0.0 & 0.0 \\
$\mathrm{CH}^{+}+\mathrm{e}$ & $7(-8)$ & -0.5 & 0.0 & $1.50(-7)$ & -0.42 & 0.0 \\
\hline
\end{tabular}

Notes. The coefficients $A, B$ and $C$ have their usual meaning (see e.g., McElroy et al. 2013). The notation $x(-y)$ denotes $x 10^{-y}$.

of $\mathrm{OH}$. The rate constants do not differ much in the three networks

UMIST - $A=3.14 \times 10^{-13}, B=2.7, C=3150(297-$ $3532 \mathrm{~K})$;

OSU $-A=3.44 \times 10^{-13}, B=2.67, C=3160(1-40000 \mathrm{~K})$; $\mathrm{KIDA}-A=3.44 \times 10^{-13}, B=2.67, C=3160(10-280 \mathrm{~K})$. However, for the reactions consuming $\mathrm{OH}$, the rate coefficients are different in the three networks, propagating into the $\mathrm{OH}$ abundances in the surface layers inside $10 \mathrm{au}$. Emission lines of molecular hydrogen turn out to be mostly within a factor of three. Many of the $\mathrm{H}_{2}$ lines discussed here originate in a thin surface layer limited in depth by the dust continuum. The high rotational line at $4.694 \mu \mathrm{m}$ as well as the rovibrational lines are optically thin similar to what was found by Nomura \& Millar (2005). This makes line flux predictions very sensitive to the exact placement of the $\mathrm{H} / \mathrm{H}_{2}$ transition in the disk model.

- HCN lines originating in the outer disk are also very robust; again, similar to the $\mathrm{CO}$ case, the chemistry here is largely molecular cloud chemistry.

- CN outer disk abundances are lower in the OSU and KIDA disk models (see Figs. 1 and 6) and the corresponding lines originating in the outer disk are systematically weaker for those networks compared to UMIST2012. One difference in the networks is the $\mathrm{CN}$ destruction reaction with oxygen, which is a factor of approximately two stronger in OSU and KIDA at low temperatures compared to UMIST2012.

- $\mathrm{OH}$ and water lines differ within a factor ten between the OSU/KIDA and UMIST2012. This is mainly due to the missing collider reactions that affect the outer lower reservoirs of these two molecules.

- The largest differences (more than one order of magnitude) are seen in line fluxes of $\mathrm{CH}^{+}$between UMIST2012 and KIDA. This is due to differences in reaction rates leading to the formation and destruction of this radical (see Table 7).

\subsection{Adsorption energies}

After having seen differences arizing from different networks, we focus now on adsorption energies that affect the gas/ice reservoirs in the disk. Collings et al. (2004) found for example that $\mathrm{CO}$ can be trapped in the polar water ice at much higher temperatures than in a non-polar $\mathrm{CO}$ ice. The dependence of chemical abundances on the specific grain surface $-\mathrm{SiO}_{2}$, polar, nonpolar - has already been noted by Bergin et al. (1995). Here, we explore systematically the effects of using different sets of adsorption energies and explore a first simple model that illustrates the effect of surface dependent adsorption energies. 

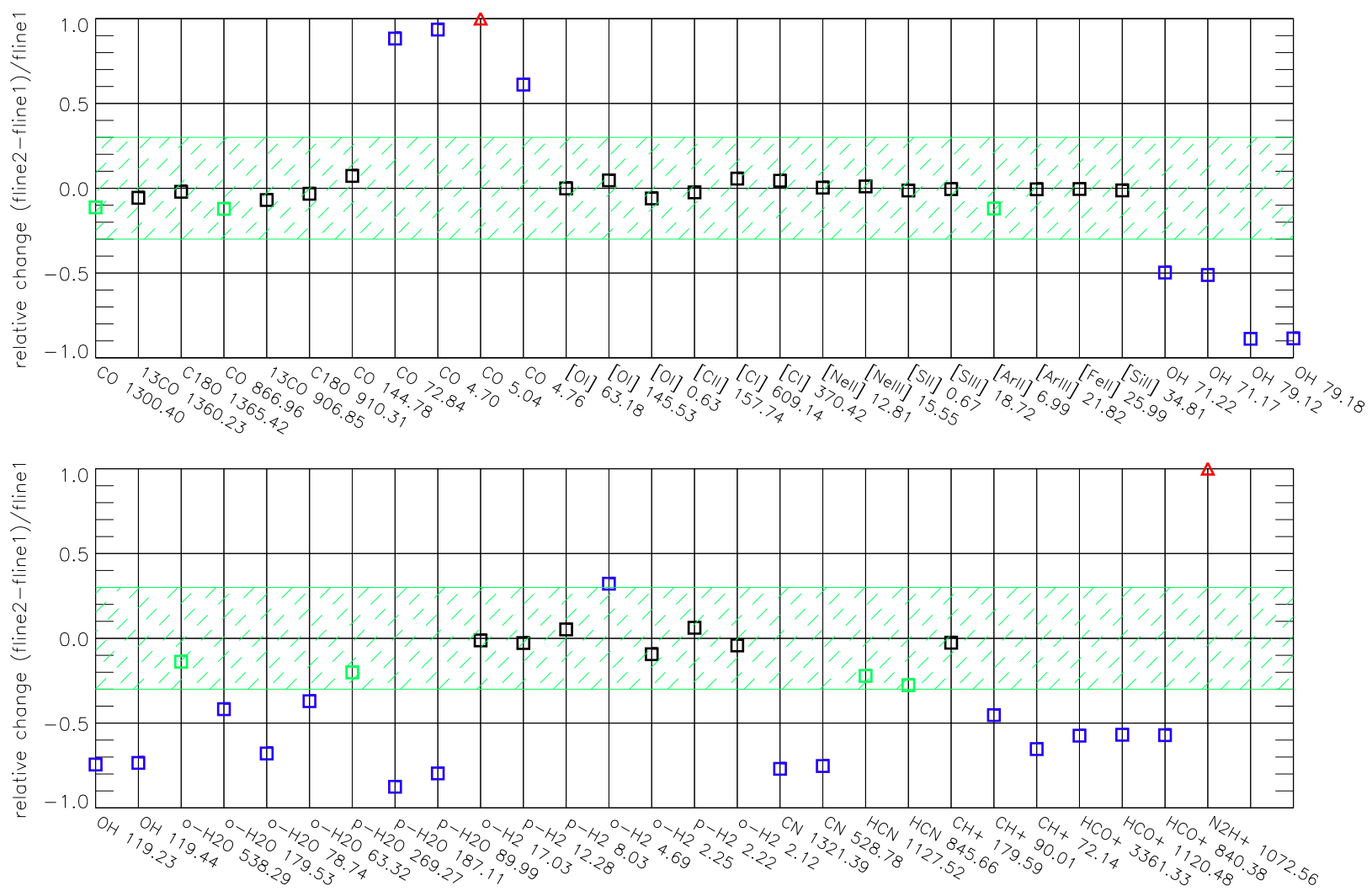

Fig. 7. Comparison of line fluxes for two databases: UMIST2012 (fline1, model 1) and OSU (fline2, model 3). Black and green squares denote differences of less than $25 \%$ and less than a factor two respectively, blue squares and red triangles denote differences larger than a factor three and ten respectively.
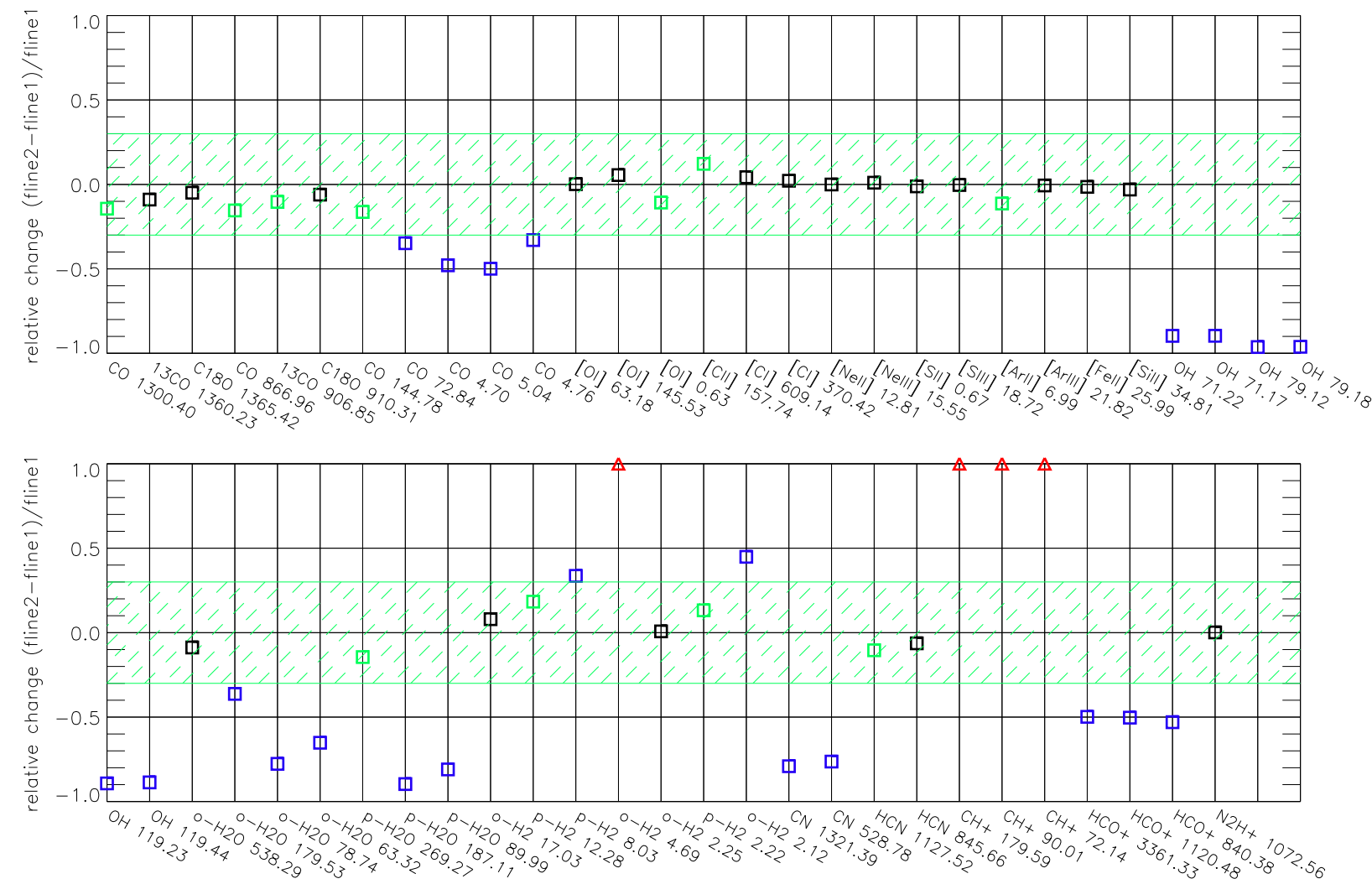

Fig. 8. Comparison of line fluxes for two databases: UMIST2012 (fline1, model 1) and KIDA (fline2, model 4). Black and green squares denote differences of less than $25 \%$ and less than a factor two respectively, blue squares and red triangles denote differences larger than a factor three and ten respectively. 
The thermal desorption rate of a species $i$ depends among other variables also on the adsorption energy $E_{\text {ads }}(i)$ (expressed in $\mathrm{K}$ )

$R=n_{\text {i\# }} v_{\mathrm{osc}}(i) \exp \left(-\frac{E_{\mathrm{ads}}(i)}{T_{\text {dust }}}\right) \mathrm{cm}^{-3} \mathrm{~s}^{-1}$,

where $v_{\mathrm{osc}}(i)$ is the oscillation frequency of species $i, n_{i \#}$ the density of desorbable species $i$ on the grain surface ${ }^{2}$, and $T_{\text {dust }}$ the temperature of the grain. The oscillation frequency depends only weakly on the adsorption energy of the species, thus making the exponential term in Eq. (3) the dominant one.

Adsorption energies measured in experiments differ largely depending on whether they are measured from ice on top of the same ice, ice mixtures or ice on bare graphite or silicate grains. Figure 9 shows two examples for values collected for $\mathrm{NH}_{3}$ and HCN ice. The set of adsorption energies from Aikawa et al. (1996) corresponds to bare carbonaceous or silicate surfaces. Alternatively, Garrod \& Herbst (2006) compiled a set of adsorption energies that is valid for non-porous water ice surfaces. Figure 9 shows that most values found in the literature indeed group around either the low bare grain value or the higher value on water ice. Values for the adsorption of a species on its own ice reside somewhere in between (see e.g., $\mathrm{NH}_{3}$ vapor enthalpy and $\mathrm{NH}_{3}$ on ammonia ice, Sandford \& Allamandola 1993). UMIST2012 recommends a set of adsorption energies that largely agrees (within 30\%) with Garrod \& Herbst (2006). The only exception among the species in common is $\mathrm{HCOOCH}_{3}$ $\left(\mathrm{GH} 06: E_{\mathrm{ads}}=6300 \mathrm{~K}\right.$, UMIST2012: $\left.E_{\mathrm{ads}}=4000 \mathrm{~K}\right)$. A more general overview of the uncertainties around adsorption energies and a critical review can be found in Cuppen et al. (2017). We compare in the following three sets of adsorption energies: Aikawa et al. (1996; model 1), Garrod \& Herbst (2006; model 5) and UMIST2012 (model 6).

Differences in the adsorption energies affect most species masses by less than a factor 2-3. However, a few species change by more than a factor of three, some even by an order of magnitude: $\mathrm{CN}, \mathrm{HCN}, \mathrm{CO}_{2}, \mathrm{NH}_{2}, \mathrm{~N}_{2}, \mathrm{~N}_{2} \mathrm{H}^{+}, \mathrm{Si}, \mathrm{SiH}$, and $\mathrm{HCN}$ ice (Fig. 10). The extent of the various ice reservoirs changes from one set of adsorption energies to the other (see Fig. 12). The most extreme case is $\mathrm{NH}_{3}$ ice where the ice line moves from 40 au ( $E_{\text {ads }}$ from Aikawa et al. 1996) to 0.3 au $\left(E_{\text {ads }}\right.$ from Garrod \& Herbst 2006). We note that a significant change in the ice line does not have to lead to a significant change of the species mass and thus the two provide complementary information. We discuss in the following the processes behind the changes in the chemistry.

- $\mathrm{CO}_{2}$ : the snow line limits the radial extent of the $\mathrm{CO}_{2}$ ring in the midplane of the disk, where water is not yet completely frozen onto the cold dust grains. The snow line changes from $\sim 1$ au to $\sim 0.3$ au for the two different values of $E_{\text {ads }}$ for water, $4800 \mathrm{~K}$ and $5700 \mathrm{~K}$. However, none of this affects the water ice reservoir since that is dominated by the mass in the outer disk.

- $\mathrm{CN}, \mathrm{HCN}, \mathrm{NH}_{2}, \mathrm{~N}_{2}$ : the adsorption energy of $\mathrm{NH}_{3}$ ice determines the radial ice line for this species. For $E_{\text {ads }}=880 \mathrm{~K}$ (Aikawa), the $\mathrm{NH}_{3}$ ice reservoir extends from 40 to $200 \mathrm{au}$ and nitrogen does not fully condense into $\mathrm{NH}_{3}$ ice. For $E_{\text {ads }}=5530 \mathrm{~K}$ (GH06, UMIST2012), all nitrogen is bound in $\mathrm{NH}_{3}$ ice between 0.3 and 200 au. With a low adsorption energy, sufficient nitrogen remains in the gas phase between

\footnotetext{
2 Details on the various thermal and non-thermal desorption processes
} can be found in Woitke et al. (2009a).


Fig. 9. Comparison between various literature values for the adsorption energy of $\mathrm{NH}_{3}$ and $\mathrm{HCN}$. White text indicates the surface on which the adsorption energy was measured, so bare carbonaceous grains, ammonia ice, water ice or an ice mixture; black text are the references.

1 and 10 au to form $\mathrm{CN}, \mathrm{HCN}, \mathrm{NH}_{2}$, and $\mathrm{N}_{2}$. Figure 10 shows that all these species have lower masses in case of the higher adsorption energy (GH06, UMIST2012), while the mass of $\mathrm{NH}_{3}$ ice increases by a factor three.

- $\mathrm{N}_{2} \mathrm{H}^{+}$: the ice line for several ice species, particularly also $\mathrm{CO}$, shifts upward beyond $20 \mathrm{au}$, if the UMIST2012 adsorption energies are used instead of the Aikawa et al. (1996) ones. This increases the abundance of $\mathrm{N}$-bearing species in the region which is oxygen poor. Since $\mathrm{N}_{2} \mathrm{H}^{+}$resides in a thin layer at the disk surface, this extra reservoir causes an increase in mass by a factor of approximately ten.

- $\mathrm{Si}, \mathrm{SiH}$ : the change in the mass of $\mathrm{Si}$ and $\mathrm{SiH}$ is related to $\mathrm{CO}_{2}$. In models with a low adsorption energy for water, the $\mathrm{CO}_{2}$ ring is extended out to a few au. In this ring, $\mathrm{CO}_{2}$ reacts with $\mathrm{Si}$ to form $\mathrm{SiO}$ which subsequently freezes out onto the cold dust grains, driving $\mathrm{Si}$ into $\mathrm{SiO}$ ice at the expense also of the $\mathrm{SiH}$ abundance. In the models with a high adsorption energy, Si remains atomic out to a few au. The $\mathrm{SiO}$ that forms is efficiently destroyed by reactions with $\mathrm{C}^{+}$into $\mathrm{Si}^{+}$which is then subsequently neutralized by charge exchange with $\mathrm{Mg}$ and $\mathrm{Na}$.

Despite the fact that several gas species masses change drastically, none of the lines studied here is affected by more than a 


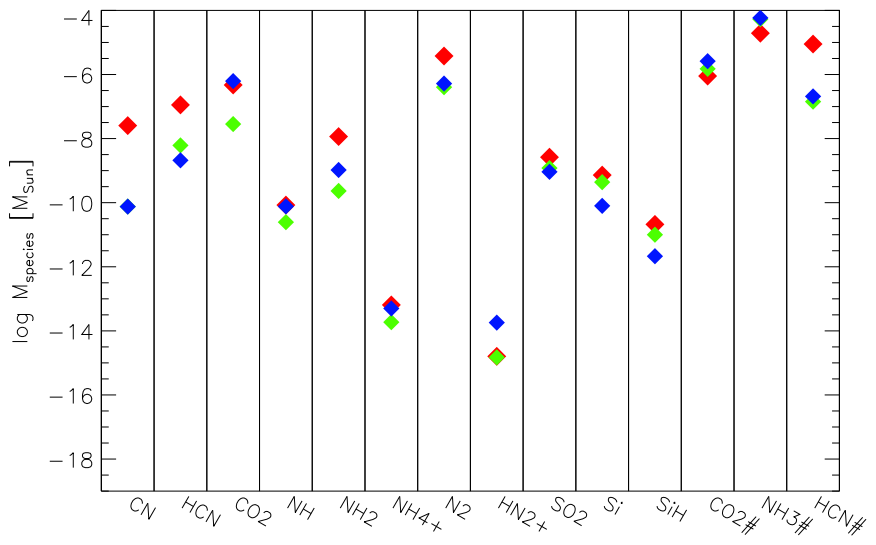

Fig. 10. Differences in species masses between three different sets of adsorption energies: Aikawa et al. (1996; red, model 1), Garrod \& Herbs (2006; green, model 5) and McElroy et al. (2013, UMIST2012; blue, model 6). Shown are only species that differ by a factor three or more.

Table 8. Adsorption energies used in the two temperature regimes: bare grains and polar ices.

\begin{tabular}{l|rlll}
\hline \hline Ice & \multicolumn{5}{|c}{$E_{\text {ads }}[\mathrm{K}]$} \\
species & $T>110 \mathrm{~K}$ & Ref. & $110 \leq T \leq 10 \mathrm{~K}$ & Ref. \\
\hline $\mathrm{CO}$ & 960 & A96 & 1150 & UMIST2012 \\
$\mathrm{H}_{2} \mathrm{O}$ & 4800 & $\mathrm{H} 09$ & 5700 & GH06 \\
$\mathrm{CO}_{2}$ & 2000 & A96 & 2990 & UMIST2012 \\
$\mathrm{CH}_{4}$ & 1360 & HH93 & 1090 & UMIST2012 \\
$\mathrm{NH}_{3}$ & 880 & A96 & 3874 & G01 \\
$\mathrm{SO}_{2}$ & 2400 & A96 & 5330 & UMIST2012 \\
$\mathrm{O}_{2}$ & 960 & as CO & 1000 & UMIST2012 \\
$\mathrm{HCN}$ & 1400 & A96 & 2050 & UMIST2012 \\
$\mathrm{N}_{2}$ & 660 & scaled CO & 1870 & G01 \\
\hline
\end{tabular}

Notes. Abbreviations for references can be found in Table A.1.

factor of two except the $\mathrm{N}_{2} \mathrm{H}^{+}$line (Figs. B.1 and B.2). Most of the lines are optically thick and/or originate in the disk surface and do not trace the chemistry changes occurring typically closer to the midplane. The only lines changing by a factor of two are the optically thin lines of $\mathrm{C}^{18} \mathrm{O}(1365.42$ and $910.31 \mu \mathrm{m})$, and the $\mathrm{CN}$ line $(528.78 \mu \mathrm{m})$. The $\mathrm{N}_{2} \mathrm{H}^{+}$line at $1072.56 \mu \mathrm{m}$ increases by more than a factor of ten if the UMIST2012 adsorption energies are used; this is related to the increase in $\mathrm{N}_{2} \mathrm{H}^{+}$ mass as shown in Fig. 10 due to the change in $\mathrm{N}_{2}$ absorption energy (GH06: $1000 \mathrm{~K}$, UMIST: $790 \mathrm{~K}$ ). Apart from the line flux changes, Fig. 11 shows that the $\mathrm{N}_{2} \mathrm{H}^{+}$density distributions and therefore also emitting regions in the disk change depending on the set of adsorption energies used.

It is reasonable to assume that the adsorption energy of a specific molecule will depend on the surface property of the grain, that is bare surfaces and/or the polarity of the ice. Hence, we ran an additional model in which we vary the adsorption energy as a function of temperature (model 7). For that we assume two temperature intervals: (1) bare grain surface values for $T>110 \mathrm{~K}$; and (2) polar ice values for $110 \mathrm{~K} \leq T \leq 10 \mathrm{~K}$. Table 8 summarizes the values and regimes for the ices used in the small chemical network. The $\mathrm{N}_{2}$ adsorption energy is now scaled by a factor 0.7 with respect to the one by Aikawa et al. (1996); such a scaling has already been proposed by Bergin \& Langer (1997). Ceccarelli \& Dominik (2005) show that such a scaling is required to match $\mathrm{H}_{2} \mathrm{D}^{+}$observations and Rab et al. (in prep.) show that it matches typical $\mathrm{N}_{2} \mathrm{H}^{+}$line fluxes from disks. Again, the disk density and thermal structure is kept constant.

Figure 13 shows the change in species masses with respect to the Aikawa adsorption energy set for those species that change by a factor three or more: $\mathrm{CN}, \mathrm{HCN}, \mathrm{CO}_{2}, \mathrm{NH}, \mathrm{NH}_{2}, \mathrm{NH}_{4}^{+}, \mathrm{N}_{2}$, $\mathrm{N}_{2} \mathrm{H}^{+}, \mathrm{O}_{2}^{+}, \mathrm{SO}, \mathrm{CO}_{2}$ ice, $\mathrm{NH}_{3}$ ice and $\mathrm{HCN}$ ice. The species masses of the temperature-dependent case sometimes follow the bare grain case and sometimes the water ice surface case. Species with high abundances in the inner disk such as $\mathrm{CO}_{2}$ stay close to the results from bare grains since this is in fact the adsorption energy that governs their behavior in the temperaturedependent case. Most other species stay close to the results from water ice surfaces since they are dominated by the behavior in the outer disk where grains are covered by water ice. A few species deviate from this, $\mathrm{N}_{2} \mathrm{H}^{+}, \mathrm{O}_{2}^{+}$and $\mathrm{SO}$. In these three cases, the temperature dependent adsorption energies always yield smaller species masses than any of the other two models. This is related to the higher value of $\mathrm{N}_{2}$ adsorption energy in the temperature range $110 \leq T \leq 10 \mathrm{~K}$ (Girardet \& Toubin 2001, on water ice), which allows nitrogen to deplete from the gas phase at smaller radii than in the other two models. This impacts many nitrogen bearing species, but also those which form through nitrogen chemistry including for example gas phase water beyond $10 \mathrm{au}$.

None of the lines in our selection changes by more than a factor two with respect to the bare grain case (Aikawa et al. 1996) except the $\mathrm{N}_{2} \mathrm{H}^{+}$line (see Fig. B.3). The latter becomes a factor six weaker in the case of temperature-dependent adsorption energies. The largest changes in the chemical composition are seen in the ice reservoir inside 100 au (Fig. 12); however most lines originate well above the surface ice line.

\subsection{Reactions of excited $\mathrm{H}_{2}$}

We discuss the compilation of reaction rates for excited $\mathrm{H}_{2}$ (denoted throughout the rest of the paper as $\mathrm{H}_{2}^{*}$ ) in Appendix A.4, where we assume a representative excitation state of $v=1$ $(E=5980 \mathrm{~K})$. It is assumed that $90 \%$ of the UV absorption leads to excited $\mathrm{H}_{2}, 10 \%$ to dissociation (Tielens \& Hollenbach 1985).

We find from our standard model that the molecular ions $\mathrm{CH}^{+}$and $\mathrm{HCO}^{+}$are the most affected species. In both cases, the key reaction is

$\mathrm{H}_{2}(v=1)+\mathrm{C}^{+} \rightarrow \mathrm{CH}^{+}+\mathrm{H}$.

We use here the updated rate from Eq. (A.5) as explained in the Appendix. The mass of $\mathrm{CH}^{+}$increases by a factor $\sim 10$ due to the presence of excited $\mathrm{H}_{2}$ chemistry. All other species masses change by less than $10 \%$. The change in $\mathrm{CH}^{+}$abundance transmits through various channels into $\mathrm{CH}_{2}^{+}, \mathrm{CH}_{3}^{+}$and all those molecular ions have a pathway to form $\mathrm{HCO}^{+}$

$$
\begin{aligned}
& \mathrm{CH}^{+}+\mathrm{H}_{2} \mathrm{O} \rightarrow \mathrm{HCO}^{+}+\mathrm{H}_{2} \\
& \mathrm{CH}_{2}^{+}+\mathrm{O} \rightarrow \mathrm{HCO}^{+}+\mathrm{H} \\
& \mathrm{CH}_{3}^{+}+\mathrm{O} \rightarrow \mathrm{HCO}^{+}+\mathrm{H}_{2}
\end{aligned}
$$

However, there are also many alternative pathways forming and destroying $\mathrm{HCO}^{+}$that do not involve $\mathrm{H}_{2}^{*}$. Hence, the species changes much less than $\mathrm{CH}^{+}$. 
I. Kamp et al.: Consistent dust and gas models for protoplanetary disks. II.
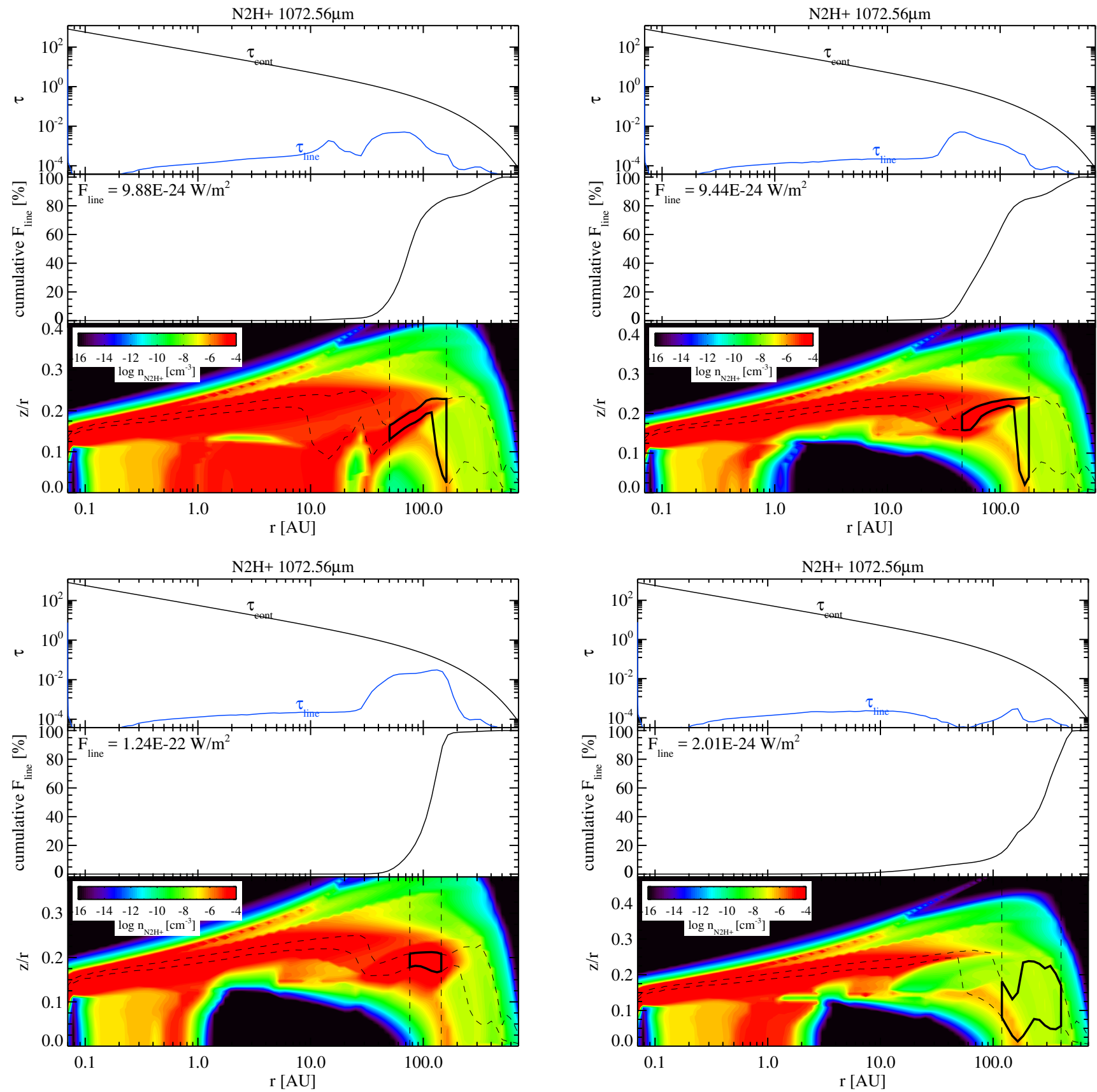

Fig. 11. $\mathrm{N}_{2} \mathrm{H}^{+} J=3-2$ line $(1072.56 \mu \mathrm{m})$ from vertical escape for the four models from top left to bottom right: the standard disk model using the set of adsorption energies from Aikawa et al. (1996; model 1), Garrod \& Herbst (2006; model 5), UMIST2012 (model 6), $T$-dependent adsorption rates (model 7). The three panels show the optical depth in the line and the continuum, the cumulative line flux as a function of radius and the box (thick black line) in which $50 \%$ of the line flux originates (15-75\% radially and vertically - dashed black lines) on the color background of the $\mathrm{N}_{2} \mathrm{H}^{+}$density distribution.

\subsection{Large versus small networks}

With the advent of ALMA, more complex molecular species and especially molecular ions will be detected in many more disks. Hence, we compare the use of small versus large networks. Again, we keep the disk density and thermal structure fixed and compare model 6 (100 species, 1288 reactions) to model 8 (235 species, 3167 reactions) using the UMIST2012 chemical database and adsorption energies.

Figures 14 and 15 show differences at the outermost radii due to the presence of more complex ices. Those affect also the outer water, $\mathrm{HCO}^{+}$and $\mathrm{HCN}$ reservoirs. Most of these changes come from new branches of chemistry allowed in the larger network such as C-chain chemistry $\left(\mathrm{C}_{n} \mathrm{H}_{m}\right)$, more links between the nitrogen, oxygen and carbon chemistry networks through $\mathrm{C}-\mathrm{N}$ and $\mathrm{N}-\mathrm{O}$ bearing species, and sulfur chemistry. In addition, the presence of additional ices and PAHs (with their ice counterpart) changes the electron abundance in the disk. Hydrocarbons change in some cases by several orders of magnitude in species mass (e.g., $\mathrm{CH}_{3}, \mathrm{CH}_{4}$ and $\mathrm{CH}_{5}^{+}$in Fig. 16). In addition, many hydronitrogens (azanes) change in mass between a factor three to ten (e.g., $\mathrm{NH}_{2}, \mathrm{NH}_{3}^{+}, \mathrm{NH}_{4}^{+}, \mathrm{N}_{2} \mathrm{H}^{+}$). Differences in molecular species mass beyond a factor of ten are also seen for $\mathrm{H}_{3}^{+}$ ( 1.2 dex $), \mathrm{NO}^{+}(\sim 1.3 \mathrm{dex}), \mathrm{H}_{3} \mathrm{O}^{+}(\sim 1 \mathrm{dex}), \mathrm{SiH}(\sim 1.8 \mathrm{dex})$, and $\mathrm{SiOH}^{+}(\sim 1 \mathrm{dex})$. Many metals and metal ions also change their species masses by more than a factor three. For the ices 

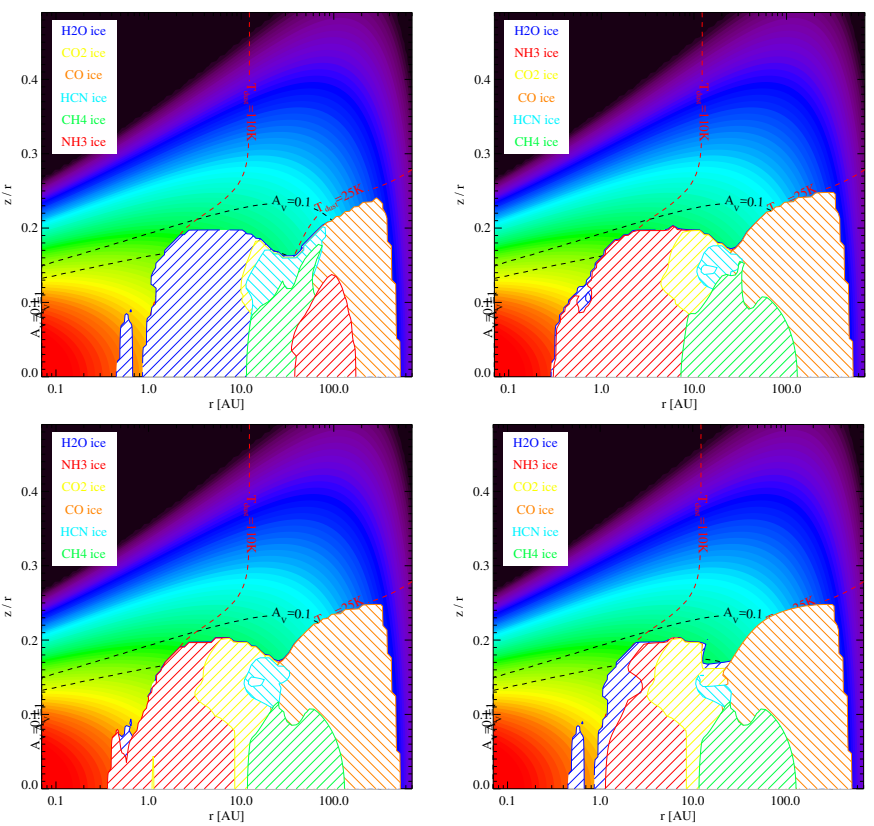

Fig. 12. Distribution of ice reservoirs plotted on top of each other in order from top to bottom of legend. Note that some ices may be partially hidden behind others. The order but not the color scheme is changed for the upper left panel to make the ammonia ice visible. From top left to bottom right: the standard disk model using the set of adsorption energies from Aikawa et al. (1996; model 1), Garrod \& Herbst (2006; model 5), UMIST2012 (model 6), $T$-dependent adsorption rates (model 7). The color scale in the background shows the total hydrogen number density in the disk model and the black dashed lines the $A_{\mathrm{V}}=0.1$ and 1 contours (minimum of radial and vertical $A_{\mathrm{V}}$ ).

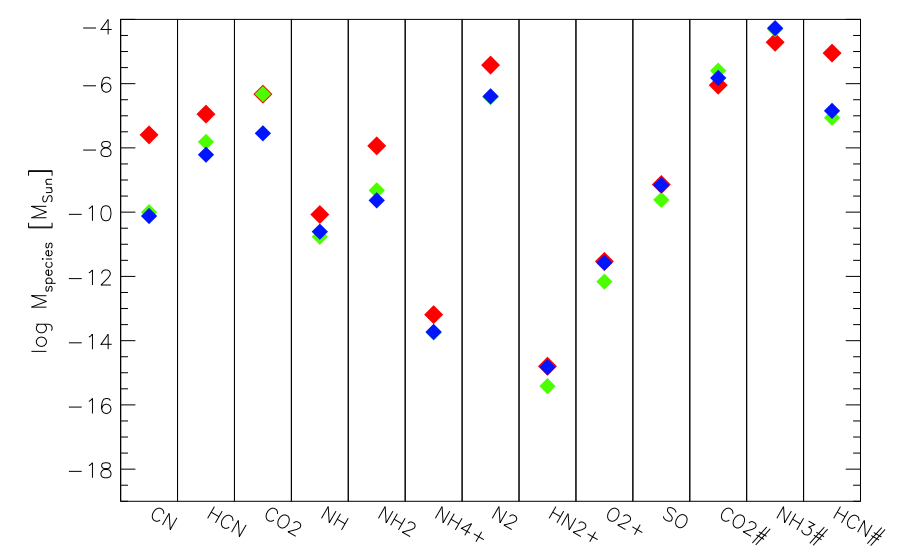

Fig. 13. Differences in species masses between $E_{\text {ads }}$ of Aikawa et al. (1996, red, model 1 - bare grains), temperature-dependent adsorption energies (green, model 7) and $E_{\text {ads }}$ of Garrod \& Herbst (2006, blue, model 5 - water ice).

in common, the largest changes are seen in $\mathrm{CH}_{4}$ ice $(\sim 1.8 \mathrm{dex})$, $\mathrm{SO}_{2}$ ice $(\sim 1.4$ dex $)$ and $\mathrm{HCN}$ ice $(\sim 1.5 \mathrm{dex})$.

Figure 17 reveals that the majority of lines investigated here do not change when we expand the chemical network to include more complex chemistry. Some lines change within a factor three, something easily buried in uncertainties within other disk input parameters; examples are the fine-structure lines of neutral carbon at 609 and $370 \mu \mathrm{m}$. The sub-mm lines of HCN decrease in the larger network by more than a factor three.

$\mathrm{HCO}^{+}$and $\mathrm{N}_{2} \mathrm{H}^{+}$lines increase by more than an order of magnitude when the larger network is considered. For $\mathrm{HCO}^{+}$,
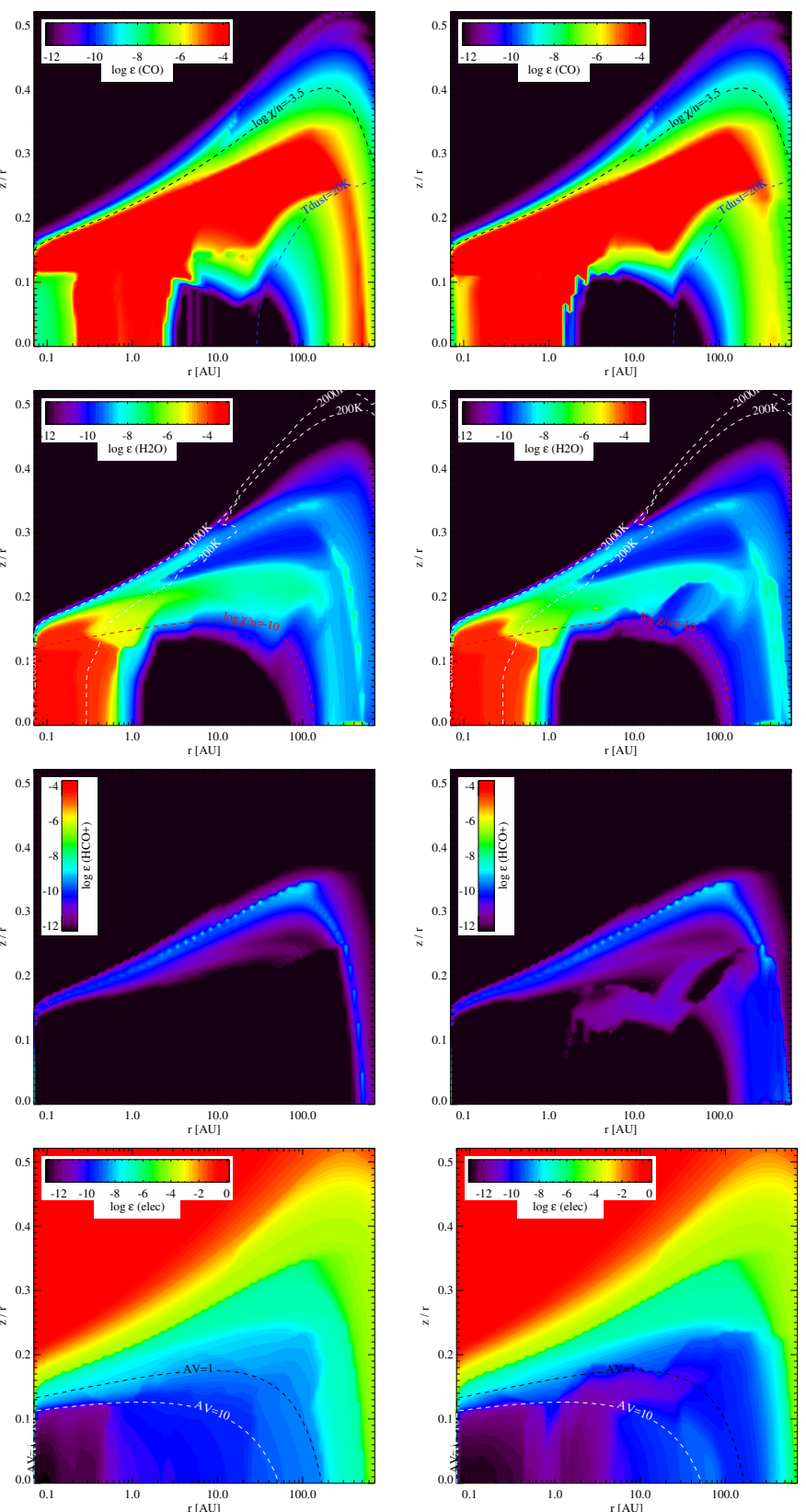

Fig. 14. Distribution of key species abundances using the small (left) and large (right) chemical network: $\mathrm{CO}, \mathrm{H}_{2} \mathrm{O}, \mathrm{HCO}^{+}$, and electrons. Contours are the same as Fig. 1.

this is due to a decrease in electron abundance in the regions where this molecule can form (see Fig. 17), especially in the outer disk beyond $100 \mathrm{au}$. The change in electron abundance (see Fig. 14) is related to the freeze out of all neutral molecules and atoms (e.g., also sulfur and iron) included in the large network; the small network comprises only freeze-out of the molecules $\mathrm{CO}, \mathrm{H}_{2} \mathrm{O}, \mathrm{CO}_{2}, \mathrm{CH}_{4}, \mathrm{NH}_{3}, \mathrm{SiO}, \mathrm{SO}_{2}, \mathrm{O}_{2}, \mathrm{HCN}$ and $\mathrm{N}_{2}$. More chemical details behind these changes are explained in Rab et al. (2017) with the caveat that they only use the large chemical network.

\section{Discussion}

Most of the results outlined above are not specific to the choice of thermo-chemical disk code. We fixed the disk structure and exploited purely changes related to the choice of chemical 
I. Kamp et al.: Consistent dust and gas models for protoplanetary disks. II.
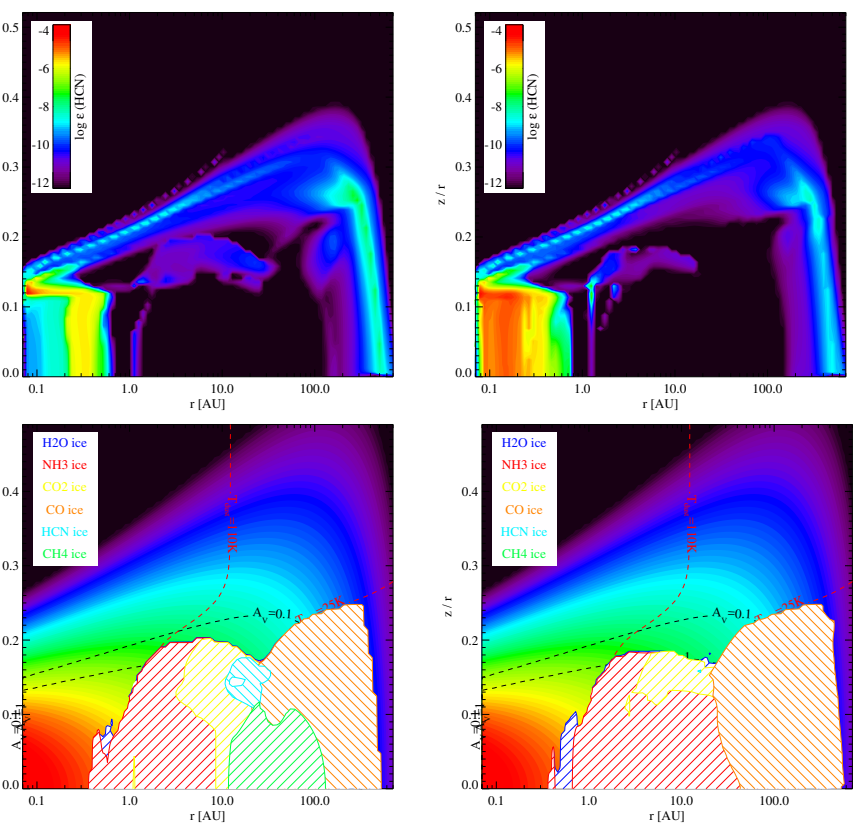

Fig. 15. Distribution of key species abundances using the small (left) and large (right) chemical network: $\mathrm{HCN}$ and ice reservoirs. Contours and legend are the same as Fig. 12.

database, set of adsorption energies and size of the network. Similar changes would show in any chemical code if it is applied to the large range of physical and irradiation conditions in disks. It has to be kept in mind that the chemical databases used in astrochemistry were originally developed for low density cold environments such as molecular clouds. Networks extending to higher temperatures more appropriate for inner disk regions have been developed (e.g., Agúndez et al. 2008; Harada et al. 2010), but are not routinely included in disk chemical models. With this work, we thus push the existing widely-used databases into regimes they have originally not been tested for.

Contrary to McElroy et al. (2013) we find large differences when comparing different chemical databases. We calculate the chemistry in environments of higher densities $\left(\gtrsim 10^{8} \mathrm{~cm}^{-3}\right)$ and temperatures (10-5000 K), while McElroy et al. (2013) used a dark cloud environment with $n\left(\mathrm{H}_{2}\right)=10^{4} \mathrm{~cm}^{-3}, T=10 \mathrm{~K}$, $A_{\mathrm{V}}=10 \mathrm{mag}$. Hence, we find differences both in the spatial distribution of species and also in the resulting line fluxes. The differences for $\mathrm{OH}$ and water between UMIST and OSU/KIDA can likely be attributed to collider reactions. In addition, many lines originating from the inner disk show changes larger than a factor two. This indicates differences in the warm chemistry between the networks; abundances of many even simple molecules change in the inner disk where gas temperatures are in excess of a $300 \mathrm{~K}$. These differences would not show up under the low density and low temperature conditions of a dark cloud.

The tests with different sets of adsorption energies shows that most atomic and molecular lines do not depend on these values. Many of these lines are optically thick and hence originate largely in the surface layers well above the ice reservoirs. However, the $\mathrm{C}^{18} \mathrm{O}$ lines are optically thin and therefore directly linked to the size and height of the $\mathrm{CO}$ ice reservoir. The fluxes and emission maps of $\mathrm{C}^{18} \mathrm{O}$ will depend on the details of how ices are treated within the chemical network. Another optically thin line is $\mathrm{CN} 528.78 \mu \mathrm{m}$. If adsorption energies from bare grains are used, the nitrogen reservoir changes significantly and the $\mathrm{CN}$ line has an additional contribution from regions inside
$100 \mathrm{au}$. Yet another optically thin line is $\mathrm{N}_{2} \mathrm{H}^{+}$. The emitting region and also column densities of this species depend crucially on the choice of $\mathrm{N}_{2}$ adsorption energy and especially also the relative difference between $\mathrm{CO}$ and $\mathrm{N}_{2}$ adsorption energies.

It has been shown by Agúndez et al. (2010) that reactions with excited $\mathrm{H}_{2}$ play an important role in the formation of $\mathrm{CH}^{+}$ in diffuse clouds and in Photon Dominated Regions (PDRs). The authors also point out the possible relevance to circumstellar disks. Our tests show now that state-to-state chemical reactions in disks affect indeed mostly $\mathrm{CH}^{+}$; the effect on other molecular ions is minor. Hence for the interpretation of line fluxes and rotational diagrams of $\mathrm{CH}^{+}$such as presented in Thi et al. (2011a) and Fedele et al. (2013), it is important to take reactions with excited $\mathrm{H}_{2}$ into account.

Semenov et al. (2004) found that especially the intermediate layers of disks where ion-molecule chemistry is active require larger chemical networks in excess of 100 species. However, they focussed largely on the ionization degree to inform MHD disk models and their model assumes that gas and dust temperatures are equal. The latter assumption leads to colder disk surface layers compared to our model. Many neutral-neutral reactions with barriers become only important for gas temperatures above $300 \mathrm{~K}$. Our comparison between the small (100 species, 1288 reactions) and large (235 species, 3167 reactions) network shows the importance of additional freeze-out due to the presence of more ice species. As Semenov et al. (2004), we note the importance of carbon chain chemistry. The new chemical pathways opened by connecting $\mathrm{C}-\mathrm{N}, \mathrm{N}-\mathrm{O}$ and sulfur chemistry affect the abundance distribution of species even in the outer disk. The emission lines affected by this are mostly $\mathrm{HCN}, \mathrm{N}_{2} \mathrm{H}^{+}$and $\mathrm{HCO}^{+}$, while the $\mathrm{CO}$ and $\mathrm{CN}$ lines stay within a factor of approximately two. Hence, for the interpretation of submm maps and emission lines of $\mathrm{HCN}, \mathrm{N}_{2} \mathrm{H}^{+}$and $\mathrm{HCO}^{+}$, we recommend the use of larger chemical networks and a careful treatment of the ionization (metal abundances, freeze-out, charge exchange and grain charging).

The effects outlined above are all related to differences in the chemical input data. It is widely known that many of the rates we use bear large uncertainties and some reaction pathways may be even debated. In addition, we did not even include surface chemistry here, a new layer of complexity with even more unknown parameters. It becomes clear that interpreting absolute column densities of fluxes from molecular lines will be affected by the specific choice of database and/or size of the network used. This poses especially a problem when comparing works from different groups using different chemical input data. It also puts a limit to the quantitative interpretation of individual line observations. A more robust approach could be a differential investigation of the impact of specific disk parameters on key observables, such as for example the flaring angle, the gas mass, the amount of irradiation. Even though the absolute column densities of specific species may not be known to better than a factor few, the relative changes should be trustable.

\section{Conclusions}

From the detailed investigation of various chemical databases, different sets of adsorption energies and sizes of chemical networks, we conclude the following key points.

Many atomic and molecular lines are very robust against changes in the chemical rates and in the size of the network. Caution, however, is required for

- $\mathrm{HCN}, \mathrm{N}_{2} \mathrm{H}^{+}$and $\mathrm{HCO}^{+}$lines (size of the network), 


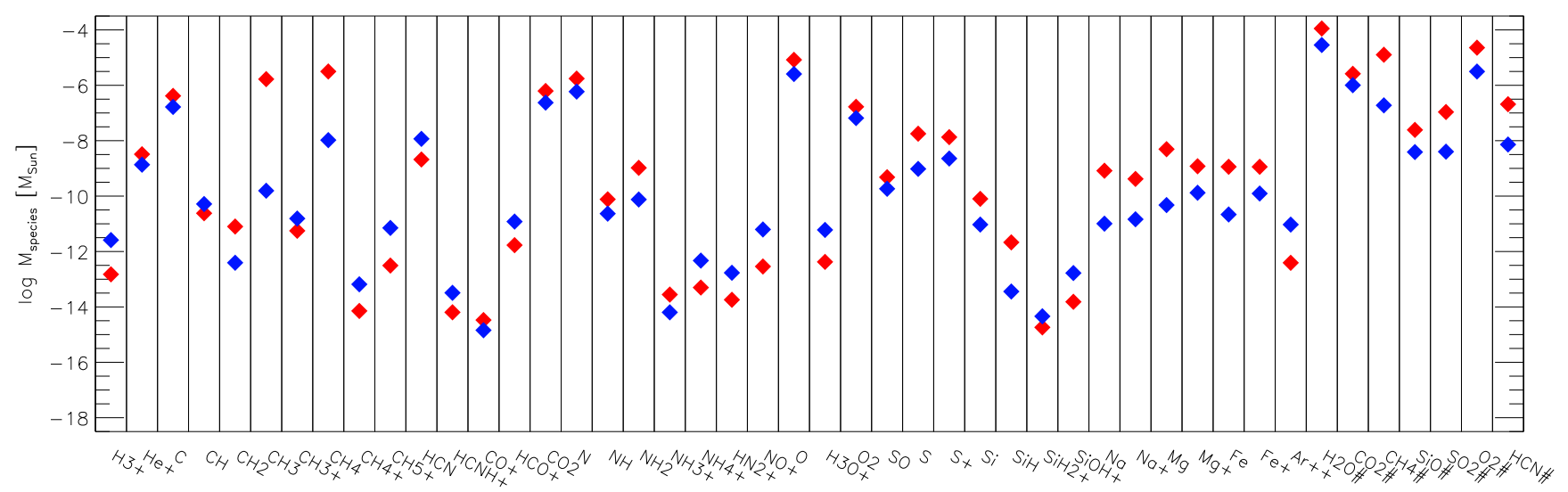

Fig. 16. Differences in species masses using the UMIST2012 database and its adsorption energies for the small (red, model 6) and large chemical network (blue, model 8).
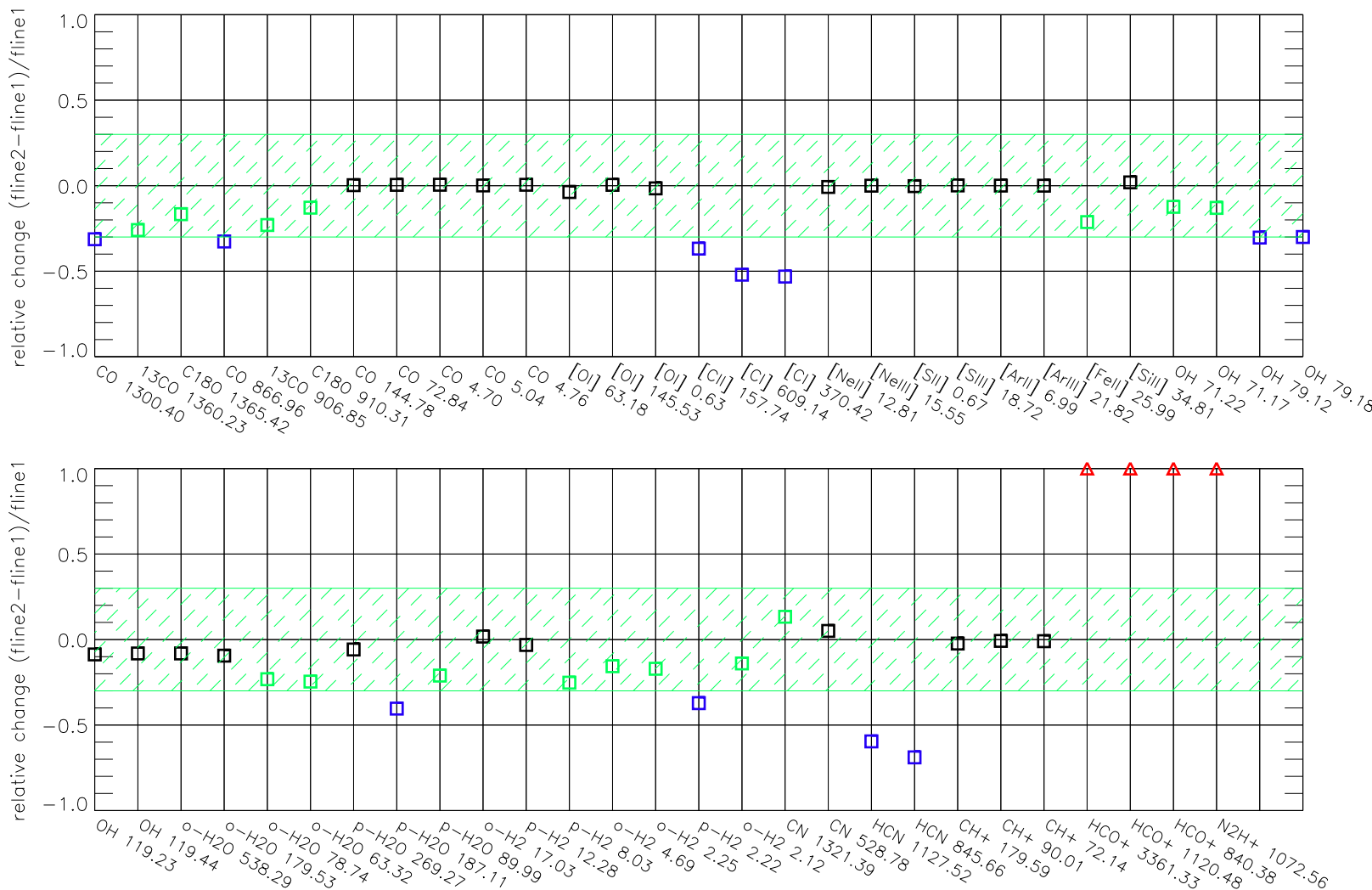

Fig. 17. Comparison of line fluxes using the UMIST2012 database and its adsorption energies for the small (fline1, model 6) and large chemical network (fline2, model 8). Black and green squares denote differences of less than $25 \%$ and less than a factor two respectively, blue squares and red triangles denote differences larger than a factor three and ten respectively.

- high excitation $\mathrm{CO}, \mathrm{CN}, \mathrm{CH}^{+}, \mathrm{H}_{2} \mathrm{O}, \mathrm{OH}$ lines (database dependency),

- $\mathrm{CH}^{+}$lines (reactions of excited $\mathrm{H}_{2}$ ),

- HCO $^{+}$lines (UMIST2006 to UMIST2012 update in rates).

Collider reactions play a major role even in the upper layers of disks. Hence, it would be good to revisit those in experiments. Special attention should be given to checking their low temperature extrapolations.

There is not a single consistent set of adsorption energies to be used for disks. Instead, we recommend a self-consistent approach, where the adsorption energy depends on the nature of the already existing ice, for example polar or non-polar. This is of minor importance for most of the observed gas lines. However, it will affect the spatial position of ice lines in the disk and thus the emitting region of the rarer $\mathrm{CO}$ isotopologues and molecular ions such as $\mathrm{HCO}^{+}$and $\mathrm{N}_{2} \mathrm{H}^{+}$.

For $\mathrm{CH}^{+}$state-to-state reactions become important in the upper layers of disks. Only very few reactions of excited molecular hydrogen have so far been investigated in detail. The here proposed simplified scheme of using the $\mathrm{H}_{2} v=1$ state and scaling the known reaction rates for $\mathrm{H}_{2} v=0$ can only be a first step.

As demonstrated here, the absolute line fluxes can be very sensitive to the specific choice of rate network. However, this will not affect studies where the sensitivity of lines is tested against specific disk parameters using the same chemical network and database. However, discrepancies in disk models for 
I. Kamp et al.: Consistent dust and gas models for protoplanetary disks. II.

specific objects from groups using different chemical networks should be taken with caution.

More recent discussions among the disk modelers and the chemical database groups start to diminish some of the discrepancies noted in this work. Hence, we expect that new database releases will bring the results in even closer agreement.

Acknowledgements. We would like to thank K. Oeberg, E. Bergin, T. Millar and E. van Dishoeck for insightful discussions during the development of this work. We also thank the anonymous referee for a careful reading of the manuscript and suggestions that improved the clarity of the figures and text. I.K., W.F.T. C.R., and P.W. acknowledge funding from the EU FP7-2011 under Grant Agreement No. 284405. C.R. also acknowledges funding by the Austrian Science Fund (FWF), project number P24790.

\section{References}

Ádámkovics, M., Glassgold, A. E., \& Meijerink, R. 2011, ApJ, 736, 143 Agúndez, M., Cernicharo, J., \& Goicoechea, J. R. 2008, A\&A, 483, 831 Agúndez, M., Goicoechea, J. R., Cernicharo, J., Faure, A., \& Roueff, E. 2010, ApJ, 713, 662

Aikawa, Y., \& Herbst, E. 2001, A\&A, 371, 1107

Aikawa, Y., Miyama, S. M., Nakano, T., \& Umebayashi, T. 1996, ApJ, 467, 684 Anicich, V. G. 1993, J. Phys. Chem. Ref. Data, 22, 1469

Antonellini, S. 2016, Ph.D. Thesis, Kapteyn Astronomical Institute, University of Groningen, Landleven 12, 9700 AV Groningen, The Netherlands

Antonellini, S., Kamp, I., Riviere-Marichalar, P., et al. 2015, A\&A, 582, A105

Aresu, G., Kamp, I., Meijerink, R., et al. 2011, A\&A, 526, A163

Aresu, G., Meijerink, R., Kamp, I., et al. 2012, A\&A, 547, A69

Avramenko, L. I., \& Krasnenkov, V. M. 1966, Bull. Acad. Sci. USSR Div. Chem. Sci. (Engl. Transl.), 15, 394

Badnell, N. R. 2006, ApJS, 167, 334

Badnell, N. R., O'Mullane, M. G., Summers, H. P., et al. 2003, A\&A, 406, 1151

Baulch, D. L., Cobos, C. J., Cox, R. A., et al. 1992, J. Phys. Chem. Ref. Data, 21, 411

Bergin, E. A., \& Langer, W. D. 1997, ApJ, 486, 316

Bergin, E. A., Langer, W. D., \& Goldsmith, P. F. 1995, ApJ, 441, 222

Bethell, T. J., \& Bergin, E. A. 2011, ApJ, 739, 78

Björk, J., Stafström, S., \& Hanke, F. 2011, J. Am. Chem. Soc., 133, 14884

Bouwman, J., Cuppen, H. M., Steglich, M., Allamandola, L. J., \& Linnartz, H. 2011a, A\&A, 529, A46

Bouwman, J., Mattioda, A. L., Linnartz, H., \& Allamandola, L. J. 2011b, A\&A, 525, A93

Ceccarelli, C., \& Dominik, C. 2005, A\&A, 440, 583

Ceccarelli, C., Dominik, C., Caux, E., Lefloch, B., \& Caselli, P. 2005, ApJ, 631, L81

Cernicharo, J., Ceccarelli, C., Ménard, F., Pinte, C., \& Fuente, A. 2009, ApJ, 703, L123

Collings, M. P., Anderson, M. A., Chen, R., et al. 2004, MNRAS, 354, 1133

Cuppen, H. M., Walsh, C., Lamberts, T., et al. 2017, Space Sci. Rev.

De Becker, M. 2013, Bull. Soc. Roy. Sci. Liège, 82, 33

Dere, K. P., Landi, E., Mason, H. E., Monsignori Fossi, B. C., \& Young, P. R. 1997, A\&AS, 125, 149

Domine, F., Cincinelli, A., Bonnaud, E., Martellini, T., \& Picaud, S. 2007, Environmental Science Technology, 41, 6033

Dutrey, A., Henning, T., Guilloteau, S., et al. 2007, A\&A, 464, 615

Eiteneer, B., \& Frenklach, M. 2003, Int. J. Chem. Kinet., 35, 391

Fedele, D., Bruderer, S., van Dishoeck, E. F., et al. 2013, A\&A, 559, A77

Fontijn, A., Shamsuddin, S. M., Crammond, D., Marshall, P., \& Anderson, W. R. 2006, Combust. Flame, 145, 543

Fu, J., \& Suuberg, E. M. 2011, J. Chem. Thermodyn., 43, 1660

Garrod, R. T., \& Herbst, E. 2006, A\&A, 457, 927

Girardet, C., \& Toubin, C. 2001, Surface Sci. Rep., 44, 159

Glassgold, A. E., Meijerink, R., \& Najita, J. R. 2009, ApJ, 701, 142

Goldfarb, J. L., \& Suuberg, E. M. 2008, J. Chem. Engng. Data, 53, 670

Harada, N., Herbst, E., \& Wakelam, V. 2010, ApJ, 721, 1570

Hasegawa, T. I., \& Herbst, E. 1993, MNRAS, 261, 83

Heays, A. N., Bosman, A. D., \& van Dishoeck, E. F. 2017, A\&A, 602, A105

Hierl, P. M., Morris, R. A., \& Viggiano, A. A. 1997, J. Chem. Phys., 106, 10145

Hily-Blant, P., Bonal, L., Faure, A., \& Quirico, E. 2013, Icarus, 223, 582

Hollenbach, D., \& McKee, C. F. 1989, ApJ, 342, 306

Hollenbach, D. J., Takahashi, T., \& Tielens, A. G. G. M. 1991, ApJ, 377, 192

Hollenbach, D., Kaufman, M. J., Bergin, E. A., \& Melnick, G. J. 2009, ApJ, 690, 1497

Jodkowski, J. T., Rayez, M.-T., \& Rayez, J.-C. 1999, J. Phys. Chem. A, 103, 3750
Jones, M. E., Barlow, S. E., Ellison, G. B., \& Ferguson, E. E. 1986, Chem. Phys Lett., 130, 218

Kamp, I., Tilling, I., Woitke, P., Thi, W., \& Hogerheijde, M. 2010, A\&A, 510, A18

Kamp, I., Thi, W.-F., Meeus, G., et al. 2013, A\&A, 559, A24

Koshi, M., Yoshimura, M., Fukuda, K., \& Matsui, H. 1990, J. Chem. Phys., 93, 8703

Kruse, T., \& Roth, P. 1997, J. Phys. Chem. A, 101, 2138

Kumar, S., Parks, D., \& Kamrin, K. 2016, ACS Nano, 10, 6552

Landini, M., \& Fossi, B. C. M. 1991, A\&AS, 91, 183

Lee, H.-H., Roueff, E., Pineau des Forets, G., et al. 1998, A\&A, 334, 1047

Lennon, M. A., Bell, K. L., Gilbody, H. B., et al. 1988, J. Phys. Chem. Ref. Data, 17,1285

McElroy, D., Walsh, C., Markwick, A. J., et al. 2013, A\&A, 550, A36

Mebel, A., Moskaleva, L. V., \& Lin, M. C. 1999, J. Mol. Struct. Theochem., 461, 223

Meijerink, R., Aresu, G., Kamp, I., et al. 2012, A\&A, 547, A68

Mészár, Z. E., Hantal, G., Picaud, S., \& Jedlovszky, P. 2013, J. Phys. Chem. C, 117,6719

Min, M., Bouwman, J., Dominik, C., et al. 2016a, A\&A, 593, A11

Min, M., Rab, C., Woitke, P., Dominik, C., \& Ménard, F. 2016b, A\&A, 585, A13

Nomura, H., \& Millar, T. J. 2005, A\&A, 438, 923

Öberg, K. I., Qi, C., Fogel, J. K. J., et al. 2010, ApJ, 720, 480

Oja, V., \& Suuberg, E. M. 1998, J. Chem. Engng. Data, 43, 486

Panić, O., \& Hogerheijde, M. R. 2009, A\&A, 508, 707

Pierson, H. O. 1993, Handbook of carbon, graphite, diamond and fullerenes (New Jersey: Noyes)

Prasad, S. S., \& Huntress, Jr., W. T. 1980, ApJS, 43, 1

Qi, C., Kessler, J. E., Koerner, D. W., Sargent, A. I., \& Blake, G. A. 2003, ApJ, 597,986

Qi, C., Öberg, K. I., \& Wilner, D. J. 2013a, ApJ, 765, 34

Qi, C., Öberg, K. I., Wilner, D. J., et al. 2013b, Science, 341, 630

Rab, C., Güdel, M., Padovani, M., et al. 2017, A\&A, 603, A96

Sandford, S. A., \& Allamandola, L. J. 1993, ApJ, 417, 815

Schöier, F. L., van der Tak, F. F. S., van Dishoeck, E. F., \& Black, J. H. 2005, A\&A, 432, 369

Semenov, D., Wiebe, D., \& Henning, T. 2004, A\&A, 417, 93

Sternberg, A., \& Dalgarno, A. 1995, ApJS, 99, 565

Thi, W.-F., van Zadelhoff, G.-J., \& van Dishoeck, E. F. 2004, A\&A, 425, 955

Thi, W.-F., Ménard, F., Meeus, G., et al. 2011a, A\&A, 530, L2

Thi, W.-F., Woitke, P., \& Kamp, I. 2011b, MNRAS, 412, 711

Thi, W. F., Kamp, I., Woitke, P., et al. 2013, A\&A, 551, A49

Thrower, J. D., Collings, M. P., Rutten, F. J. M., \& McCoustra, M. R. S. 2009a, MNRAS, 394, 1510

Thrower, J. D., Collings, M. P., Rutten, F. J. M., \& McCoustra, M. R. S. 2009b, J. Chem. Phys., 131, 244711

Thrower, J. D., Friis, E. E., Skov, A. L., et al. 2013, J. Phys. Chem. C, 117, 13520

Tielens, A. G. G. M., \& Hollenbach, D. 1985, ApJ, 291, 722

Tielens, A. G. G. M., Allamandola, L. J., Barker, J. R., \& Cohen, M. 1987, in NATO Advanced Science Institutes (ASI) Series C 191, eds. A. Leger, L. D'Hendecourt, \& N. Boccara, 273

Tsang, W. 1987, J. Phys. Chem. Ref. Data, 16

Tsang, W., \& Hampson, R. F. 1986, J. Phys. Chem. Ref. Data, 15

van Dishoeck, E. F. 1990, in The Evolution of the Interstellar Medium, ed. L. Blitz, ASP Conf. Ser., 12, 207

van Dishoeck, E. F., Jonkheid, B., \& van Hemert, M. C. 2006, Faraday Discussions, 133, 231

Vasyunin, A. I., Sobolev, A. M., Wiebe, D. S., \& Semenov, D. A. 2004, Astron. Lett., 30, 566

Vasyunin, A. I., Semenov, D., Henning, T., et al. 2008, ApJ, 672, 629

Verner, D. A., \& Yakovlev, D. G. 1995, A\&AS, 109, 125

Visser, R., Geers, V. C., Dullemond, C. P., et al. 2007, A\&A, 466, 229

Wakelam, V., Herbst, E., Loison, J.-C., et al. 2012, ApJS, 199, 21

Woitke, P., Kamp, I., \& Thi, W.-F. 2009a, A\&A, 501, 383

Woitke, P., Thi, W.-F., Kamp, I., \& Hogerheijde, M. R. 2009b, A\&A, 501, L5

Woitke, P., Riaz, B., Duchêne, G., et al. 2011, A\&A, 534, A44

Woitke, P., Min, M., Pinte, C., et al. 2016, A\&A, 586, A103

Woodall, J., Agúndez, M., Markwick-Kemper, A. J., \& Millar, T. J. 2007, A\&A, 466, 1197

Zanchet, A., Agúndez, M., Herrero, V. J., Aguado, A., \& Roncero, O. 2013a, AJ, 146,125

Zanchet, A., Godard, B., Bulut, N., et al. 2013b, ApJ, 766, 80

Zatsarinny, O., Gorczyca, T. W., Korista, K. T., Badnell, N. R., \& Savin, D. W. 2003, A\&A, 412, 587

Zhu, W., Zhang, J. Z. H., Zhang, Y. C., Zhang, Y. B., \& Zhan, L. X. 1998, J. Chem. Phys., 108, 3509 


\section{Appendix A: Chemical reaction rates}

Next to the standard rates from chemical databases such as UMIST, OSU or KIDA, we use the additional set of reaction rates described below. Some of them are added to the standard set of rates, some overwrite rates from the databases if this option is invoked. This is indicated in the respective subsections. Abbreviations for the references are listed in Table A.1.

\section{A.1. Chemistry different from UMIST}

A key reaction is the $\mathrm{H}_{2}$ formation which is hardcoded in ProDiMo. The reaction rate and implementation is described in Woitke et al. (2009a).

\section{A.2. Chemistry added to UMIST}

Reactions which we include in addition to UMIST are given in Table A.2. Most of them describe the photodissociation of molecular ions; these latter rates are taken from Heays et al. (2017). We use the formalism of Woitke et al. (2009a) to implement adsorption of gas phase species onto grains and thermal and non-thermal desorption.

\section{A.3. Photochemistry}

We calculate the photo rates from using the local radiation field from the 2D continuum radiative transfer (Kamp et al. 2010) and the photoionization and - dissociation cross sections from the Leiden database (van Dishoeck et al. 2006; Heays et al. 2017). These rates replace the standard UMIST photo rates even if the UMIST database is chosen.

\section{A.4. Chemistry of excited $\mathrm{H}_{2}$}

Reactions of excited $\mathrm{H}_{2}\left(\mathrm{H} 2 \mathrm{EXC}, \mathrm{H}_{2}^{*}\right)$ are neither included in UMIST2006 nor in UMIST2012. They can be important in disks, especially at the surface and thus have been included in Reactions.in. The basic assumption is that the vibrational energy of the excited $\mathrm{H}_{2}$ can be entirely used to overcome a potential reaction barrier (Tielens \& Hollenbach 1985). While this might be a reasonable assumption for low barriers, it may overestimate the rates for reactions with a high barrier. In any case all those rates should be treated as guesses at most. In the absence of any better rates, the reaction rate of a species with $\mathrm{H}_{2}$ is simply modified by subtracting the energy corresponding to the first vibrational excited level $v=1,5980 \mathrm{~K}$.

The collisional de-excitation rate (in units of $\mathrm{cm}^{3} \mathrm{~s}^{-1}$ ) of the pseudo excited state (effective quantum number $v=6$ ) $\mathrm{H}_{2}^{*}$ by collisions with $\mathrm{H}$ and $\mathrm{H}_{2}$ is taken from Tielens \& Hollenbach (1985) as one-sixth of the collisional de-excitation rate from $v=1, \gamma_{10}^{\mathrm{H}, \mathrm{H}_{2}}$

$R_{u l}^{\mathrm{H}}=2.887 \times 10^{-12}\left(\frac{T}{300}\right)^{0.5} \exp (-1000 / T)$,

$R_{u l}^{\mathrm{H}_{2}}=4.042 \times 10^{-12}\left(\frac{T}{300}\right)^{0.5} \exp (-18100 /(T+1200))$,

We note that Tielens \& Hollenbach (1985) provide in their Table 9 a de-excitation rate for collisions with atomic hydrogen that is a factor 0.67 smaller than this. The collisional excitation rates (in units of $\mathrm{cm}^{3} \mathrm{~s}^{-1}$ ) are the inverse of these de-excitation
Table A.1. List of reference abbreviations.

\begin{tabular}{l|l}
\hline \hline Abbreviation & Reference \\
\hline A93 & Anicich (1993) \\
A96 & Aikawa et al. (1996) \\
AG-estimate & Al Glassgold (priv. comm.) \\
B06 & Badnell (2006) \\
BC92 & Baulch et al. (1992) \\
EF03 & Eiteneer \& Frenklach (2003) \\
FS06 & Fontijn et al. (2006) \\
G01 & Girardet \& Toubin (2001) \\
H17 & Heays et al. (2017) \\
HH93 & Hasegawa \& Herbst (1993) \\
HM89 & Hollenbach \& McKee (1989) \\
HM97 & Hierl et al. (1997) \\
HTT91 & Hollenbach et al. (1991) \\
H09 & Hollenbach et al. (2009) \\
JB86 & Jones et al. (1986) \\
JR99 & Jodkowski et al. (1999) \\
KR97 & Kruse \& Roth (1997) \\
KY90 & Koshi et al. (1990) \\
L88 & Lennon et al. (1988) \\
LF91 & Landini \& Fossi (1991) \\
MM99 & Mebel et al. (1999) \\
TH85 & Tielens \& Hollenbach (1985) \\
TH86 & Tsang \& Hampson (1986) \\
T87 & Tsang (1987) \\
vD08 & van Dishoeck et al. (2006) \\
VY95 & Verner \& Yakovlev (1995) \\
ZZ98 & Zhu et al. (1998) \\
\hline & \\
\end{tabular}

rates (Woitke et al. 2009a) using the energy of the pseudo-level for vibrationally excited $\mathrm{H}_{2}, E_{v}=2.6 \mathrm{eV}$,

$R_{l u}^{\mathrm{H}}=R_{u l}^{\mathrm{H}} \exp \left(-E_{v} / k T_{\mathrm{gas}}\right)$,

$R_{l u}^{\mathrm{H}_{2}}=R_{u l}^{\mathrm{H}_{2}} \exp \left(-E_{v} / k T_{\text {gas }}\right)$,

Other rates are taken explicitly from their Table 9.

Agúndez et al. (2010) use for the reaction $\mathrm{H}_{2}^{*}+\mathrm{C}^{+} \rightarrow$ $\mathrm{CH}^{+}+\mathrm{H}$ a constant Langevin rate coefficient of $1.6 \times$ $10^{-9} \mathrm{~cm}^{3} \mathrm{~s}^{-1}$. Figure 10 of Hierl et al. (1997) suggest a possible weak temperature dependence. Zanchet et al. (2013b) performed quantum calculations to derive state-to-state reaction rates for the system $\mathrm{C}^{+}$and $\mathrm{H}_{2}$. In the following, we neglect the formation excitation of $\mathrm{CH}^{+}$and use the parametrized rate from Zanchet et al. (2013a) for $\mathrm{H}_{2}(v=1)$ (Table 3). To bring it into the usual form, we present here a simple Arrhenius fit

$R=3.87 \times 10^{-10}\left(\frac{T}{300}\right)^{-0.136} \exp (-4.33 / T) \mathrm{cm}^{3} \mathrm{~s}^{-1}$.

The theoretical calculations are a factor of four lower than the laboratory work from Hierl et al. (1997; Fig. A.1). The newer rate is only used in Sect. 3.5 discussing the effect of excited $\mathrm{H}_{2}$ on the chemistry.

In addition to those reactions, we add

$\mathrm{H}_{2}^{*}+\mathrm{CN} \rightarrow \mathrm{HCN}+\mathrm{H}$

$\mathrm{H}_{2}^{*}+\mathrm{He}^{+} \rightarrow \mathrm{H}^{+}+\mathrm{H}+\mathrm{He}$,

taken from Zhu et al. (1998) and Jones et al. (1986), respectively. In the latter case, $R=0.18-1.8 \times 10^{-9} \mathrm{~cm}^{3} / \mathrm{s}$ and we approximate that with $0.5 \times 10^{-9} \mathrm{~cm}^{3} / \mathrm{s}$.

$\mathrm{H}_{2}^{*}+\mathrm{C}_{2} \rightarrow \mathrm{C}_{2} \mathrm{H}+\mathrm{H}$

$\mathrm{H}_{2}^{*}+\mathrm{C}_{2} \mathrm{H} \rightarrow \mathrm{C}_{2} \mathrm{H}_{2}+\mathrm{H}$, 
I. Kamp et al.: Consistent dust and gas models for protoplanetary disks. II.

Table A.2. Rate constants for reactions added on top of the UMIST database.

\begin{tabular}{lrrrll}
\hline \hline Reaction & $A$ & $B$ & $C$ & Temperature range & Reference \\
\hline $\mathrm{CH}_{5}^{+}+h v \rightarrow \mathrm{CH}_{4}^{+}+\mathrm{H}$ & $3.00(-11)$ & 0.0 & 2.0 & $10.0-41000.0$ & $\mathrm{H} 17$ \\
$\mathrm{CH}_{5}^{+}+h v \rightarrow \mathrm{CH}_{3}^{+}+\mathrm{H}_{2}$ & $3.00(-11)$ & 0.0 & 2.0 & $10.0-41000.0$ & $\mathrm{H} 17$ \\
$\mathrm{H}_{2} \mathrm{O}+h v \rightarrow \mathrm{O}+\mathrm{H}_{2}$ & $8.89(-11)$ & 3.90 & 4.12 & $10.0-41000.0$ & $\mathrm{H} 17$ \\
$\mathrm{H}_{2} \mathrm{O}^{+}+h v \rightarrow \mathrm{O}+\mathrm{H}_{2}^{+}$ & $5.00(-13)$ & 0.0 & 2.0 & $10.0-41000.0$ & $\mathrm{H} 17$ \\
$\mathrm{H}_{2} \mathrm{O}^{+}+h v \rightarrow \mathrm{O}^{+}+\mathrm{H}_{2}$ & $5.00(-13)$ & 0.0 & 2.0 & $10.0-41000.0$ & $\mathrm{H} 17$ \\
$\mathrm{H}_{3} \mathrm{O}^{+}+h v \rightarrow \mathrm{H}_{2} \mathrm{O}+\mathrm{H}^{+}$ & $2.00(-11)$ & 0.0 & 2.0 & $10.0-41000.0$ & $\mathrm{H} 17$ \\
$\mathrm{H}_{3} \mathrm{O}^{+}+h v \rightarrow \mathrm{OH}+\mathrm{H}_{2}^{+}$ & $1.00(-11)$ & 0.0 & 2.0 & $10.0-41000.0$ & $\mathrm{H} 17$ \\
$\mathrm{H}_{3} \mathrm{O}^{+}+h v \rightarrow \mathrm{H}_{2} \mathrm{O}^{+}+\mathrm{H}$ & $2.00(-11)$ & 0.0 & 2.0 & $10.0-41000.0$ & $\mathrm{H} 17$ \\
$\mathrm{H}_{3} \mathrm{O}^{+}+h v \rightarrow \mathrm{OH}^{+}+\mathrm{H}_{2}$ & $2.00(-11)$ & 0.0 & 2.0 & $10.0-41000.0$ & $\mathrm{H} 17$ \\
$\mathrm{SiOH}^{+}+h v \rightarrow \mathrm{SiO}^{+}+\mathrm{H}$ & $5.00(-11)$ & 0.0 & 2.0 & $10.0-41000.0$ & $\mathrm{H} 17$ \\
$\mathrm{NH}^{+}+h v \rightarrow \mathrm{N}^{+}+\mathrm{H}$ & $5.40(-11)$ & 0.0 & 1.64 & $10.0-41000.0$ & vD08 \\
$\mathrm{C}^{+}+\mathrm{SiO} \rightarrow \mathrm{SiO}^{+}+\mathrm{C}$ & $5.40(-10)$ & 0.0 & 0.0 & $10.0-41000.0$ & TH85 \\
$\mathrm{H}_{2}+\mathrm{H}_{2} \rightarrow \mathrm{H}_{2}+\mathrm{H}+\mathrm{H}$ & $2.30(-11)$ & 1.25 & 65000.0 & $10.0-41000.0$ & TH85 \\
$\mathrm{CO}+\mathrm{H} \rightarrow \mathrm{HCO}$ & $5.29(-34)$ & 0.0 & 370.0 & $10.0-41000.0$ & NIST \\
\hline
\end{tabular}

Notes. The coefficients $A, B$, and $C$ have their usual meaning (see e.g., McElroy et al. 2013). The notation $x(y)$ denotes $x 10^{y}$.

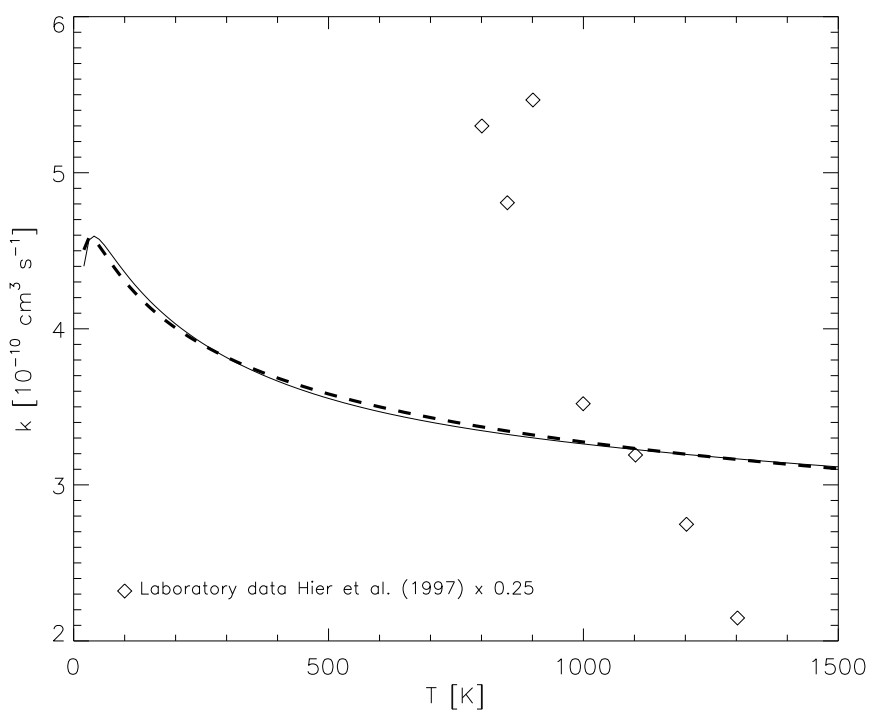

Fig. A.1. Comparison of the theoretically calculated rate A.7 (solid line, Zanchet et al. 2013a), the laboratory data scaled by a factor 0.25 (diamonds, Hierl et al. 1997) and the fit presented here (dashed line).

are taken from NIST (Kruse \& Roth 1997; Eiteneer \& Frenklach 2003). The activation barriers of $4000 \mathrm{~K}, 460.6 \mathrm{~K}$ (respectively) are set to zero.

$\mathrm{H}_{2}^{*}+\mathrm{CH}_{2} \rightarrow \mathrm{CH}_{3}+\mathrm{H}$,

$\mathrm{H}_{2}^{*}+\mathrm{CH}_{3} \rightarrow \mathrm{CH}_{4}+\mathrm{H}$,

are taken from NIST (Tsang \& Hampson 1986; Baulch et al. 1992). The first one has only an upper limit and we use that for the rate and set the activation barrier of $6400 \mathrm{~K}$ to $420 \mathrm{~K}$. The activation barrier of $4740 \mathrm{~K}$ for the second one is set to zero.

$\mathrm{H}_{2}^{*}+\mathrm{CH}_{3} \mathrm{O} \rightarrow \mathrm{CH}_{3} \mathrm{OH}+\mathrm{H}$,

$\mathrm{H}_{2}^{*}+\mathrm{CH}_{2} \mathrm{OH} \rightarrow \mathrm{CH}_{3} \mathrm{OH}+\mathrm{H}$,

are taken from NIST (Jodkowski et al. 1999; Tsang 1987). The activation barriers of $2470 \mathrm{~K}, 6720 \mathrm{~K}$ (respectively) are set to zero and $740 \mathrm{~K}$ respectively.

$\mathrm{H}_{2}^{*}+\mathrm{N} \rightarrow \mathrm{NH}+\mathrm{H}$,

$\mathrm{H}_{2}^{*}+\mathrm{NH} \rightarrow \mathrm{NH}_{2}+\mathrm{H}$,

$\mathrm{H}_{2}^{*}+\mathrm{NH}_{2} \rightarrow \mathrm{NH}_{3}+\mathrm{H}$, are taken from NIST (Koshi et al. 1990; Fontijn et al. 2006; Mebel et al. 1999). The activation barriers of $16600 \mathrm{~K}, 7760 \mathrm{~K}$, $3610 \mathrm{~K}$ (respectively) are set to $12115 \mathrm{~K}, 1802 \mathrm{~K}$ and zero respectively.

$\mathrm{H}_{2}^{*}+\mathrm{C} \rightarrow \mathrm{CH}+\mathrm{H}$,

$\mathrm{H}_{2}^{*}+\mathrm{CH} \rightarrow \mathrm{CH}_{2}+\mathrm{H}$,

are taken from UMIST2006 and their activation barriers of $11700 \mathrm{~K}$ and $1943 \mathrm{~K}$ are set to $5720 \mathrm{~K}$ and zero respectively.

$\mathrm{H}_{2}^{*}+\mathrm{O} \rightarrow \mathrm{OH}+\mathrm{H}$

$\mathrm{H}_{2}^{*}+\mathrm{OH} \rightarrow \mathrm{H}_{2} \mathrm{O}+\mathrm{H}$,

$\mathrm{H}_{2}^{*}+\mathrm{O}_{2} \rightarrow \mathrm{OH}+\mathrm{OH}$,

are taken from UMIST2006 and their activation barriers of $3150 \mathrm{~K}, 1736 \mathrm{~K}, 21890 \mathrm{~K}$ are set to zero, zero and $15910 \mathrm{~K}$ respectively.

$\mathrm{H}_{2}^{*}+\mathrm{H} \rightarrow \mathrm{H}+\mathrm{H}+\mathrm{H}$,

$\mathrm{H}_{2}^{*}+\mathrm{H}_{2} \rightarrow \mathrm{H}_{2}+\mathrm{H}+\mathrm{H}$,

$\mathrm{H}_{2}^{*}+\mathrm{H}_{2}^{*} \rightarrow \mathrm{H}_{2}+\mathrm{H}+\mathrm{H}$,

are taken from UMIST2006 and their activation barriers of $55000 \mathrm{~K}, 84100 \mathrm{~K}, 84100 \mathrm{~K}$ are set to $49020 \mathrm{~K}, 78120 \mathrm{~K}$, and $72260 \mathrm{~K}$.

\section{A.5. Collider reactions}

Even though UMIST2006 contains collider (three-body reactions, CL), the UMIST2012 rate file does not. There are 32 collider reactions in UMIST2006 (\#4552-\#4583). After discussion with T. Millar, we decided to append them to the UMIST2012 data file.

\section{A.6. PAH chemistry}

PAHs participate in charge exchange reactions with other gasphase species or the ionized PAHs can recombine with electrons. Therefore PAHs are a key species to the modeling of the gas heating and key to the determination of the ionisation fraction in disks. An example of the role of PAHs is for example that negative PAHs can lock a large fraction of the free electrons, preventing them to recombine with $\mathrm{HCO}^{+}$or $\mathrm{N}_{2} \mathrm{H}^{+}$, two commonly detected species in protoplanetary disks. The PAH reactions are 
Table A.3. Measured and computed (Mészár) PAH desorption energies.

\begin{tabular}{|c|c|c|c|c|c|c|c|c|}
\hline Name & Formula & Oja98 & Thower09 & $\begin{array}{r}\text { Domine } 07 \\
E_{\mathrm{d}}\end{array}$ & $\begin{array}{l}\text { Fu11 } \\
{[\mathrm{K}]}\end{array}$ & Goldfarb08 & Meszar13 & Thower13 \\
\hline benzene & $\mathrm{C}_{6} \mathrm{H}_{6}$ & & 5431 & & & & & \\
\hline naphtalene & $\mathrm{C}_{10} \mathrm{H}_{8}$ & & & & & & 8448 & \\
\hline acenaphthylene & $\mathrm{C}_{12} \mathrm{H}_{8}$ & & & & & $8298 \pm 989$ & & \\
\hline acenaphthene & $\mathrm{C}_{12} \mathrm{H}_{10}$ & & & & & $9470 \pm 269$ & & \\
\hline fluorene & $\mathrm{C}_{13} \mathrm{H}_{10}$ & & & & & $1059 \pm 229$ & & \\
\hline anthracene & $\mathrm{C}_{14} \mathrm{H}_{10}$ & 12068 & & & & $11848 \pm 399$ & & \\
\hline phenanthrene & $\mathrm{C}_{14} \mathrm{H}_{10}$ & 10860 & & 10862 & & & & \\
\hline fluoranthene & $\mathrm{C}_{16} \mathrm{H}_{10}$ & & & & & $11658 \pm 332$ & & \\
\hline pyrene & $\mathrm{C}_{16} \mathrm{H}_{10}$ & 12442 & & & & $11762 \pm 392$ & & \\
\hline 2,3-benzofluorene & $\mathrm{C}_{17} \mathrm{H}_{12}$ & 14397 & & & & & & \\
\hline naphthacene & $\mathrm{C}_{18} \mathrm{H}_{12}$ & 15218 & & & & $15006 \pm 350$ & & \\
\hline perylene & $\mathrm{C}_{20} \mathrm{H}_{12}$ & 16003 & & & & $15175 \pm 98$ & & \\
\hline benzo[a]phenanthrene & $\mathrm{C}_{18} \mathrm{H}_{12}$ & & & & & $13224 \pm 430$ & & \\
\hline benzo[a]pyrene & $\mathrm{C}_{20} \mathrm{H}_{12}$ & & & & & $13633 \pm 375$ & & \\
\hline benzo[b]fluoranthene & $\mathrm{C}_{20} \mathrm{H}_{12}$ & & & & 14337 & & & \\
\hline benzo[k]fluoranthene & $\mathrm{C}_{20} \mathrm{H}_{12}$ & & & & 14663 & & & \\
\hline benzo[ghi]perylene & $\mathrm{C}_{22} \mathrm{H}_{12}$ & & & & 15448 & & & \\
\hline indeno $[1,2,3$-cd]pyrene & $\mathrm{C}_{22} \mathrm{H}_{12}$ & & & & 15906 & & & \\
\hline dibenz $[\mathrm{a}, \mathrm{h}]$ anthracene & $\mathrm{C}_{22} \mathrm{H}_{14}$ & & & & 16667 & & & \\
\hline pentacenene & $\mathrm{C}_{22} \mathrm{H}_{14}$ & 18936 & & & & & & \\
\hline coronene & $\mathrm{C}_{24} \mathrm{H}_{12}$ & 16063 & & & & & & 19727 \\
\hline
\end{tabular}

Notes. Oja98: Oja \& Suuberg (1998); Thower09: Thrower et al. (2009b); Domine07: Domine et al. (2007); Fu11: Fu \& Suuberg (2011); Goldfarb08: Goldfarb \& Suuberg (2008); Meszar13: Mészár et al. (2013); Thrower13: Thrower et al. (2013).

described in details in Thi et al. (in prep.). PAHs can adsorb onto the surfaces of grains and desorb through photons or thermal heating depending on their sizes. PAH freeze-out can modify the heating-cooling balance as well as the ionisation fraction in disks. The ionisation balance is calculated using the local UV radiation field (Woitke et al. 2011). The models described in this paper use circumcoronene $\left(\mathrm{C}_{54} \mathrm{H}_{18}\right)$ as the representative PAH. Circumcoronene is a large and compact PAH (pericondensed, superaromatic) and the electron delocalization adds to its stability against photodissociation (Tielens et al. 1987; Visser et al. 2007; De Becker 2013).

\section{A.6.1. PAH freeze-out and desorption}

PAHs can adsorb onto grain surfaces coated with water ice or on bare silicate grains. In dense molecular clouds, weak absorption features have been attributed to PAHs frozen in water ice mantles (Bouwman et al. 2011a). Bouwman et al. (2011b) estimated that the $\mathrm{PAH}_{\text {ice }} / \mathrm{H}_{2} \mathrm{O}_{\text {ice }}$ ratio can reach as much as $2 \%$. Assuming a water ice abundance of $\sim 10^{-5}$, the PAH\# (PAHs adsorbed on dust surfaces) abundance is $\sim 2 \times 10^{-7}$, which suggests that all the PAHs are removed from the gas phase (the total PAH abundance is estimated to be $\sim 3 \times 10^{-7}$ ). The standard PAH used in the models presented here is circumcoronene although one can choose also larger condensed PAHs such as circumcircumcoronene $\left(\mathrm{C}_{96} \mathrm{H}_{24}\right)$, which are even more stable against photodissociation than circumcoronene.

In the absence of measured desorption rates for all individual PAHs, we assume a linear dependance of the desorption energy on the number of carbon and hydrogen atoms of the PAH based on the method of fragment constant. The linear behavior is consistent with the additivity of van der Waals interactions (Björk et al. 2011). Adsorption (desorption) energies $E_{\text {ads }}$ measured in the laboratory vary from $E_{\text {ads }} / k \simeq 5600 \mathrm{~K}$ for benzene $\mathrm{C}_{6} \mathrm{H}_{6}$ (Thrower et al. 2009a) up to $E_{\text {ads }} / k \simeq 18900 \mathrm{~K}$ for pentacenene $\mathrm{C}_{22} \mathrm{H}_{14}$ (Oja \& Suuberg 1998). Table A.3 summarises the adsorption (desorption) energies for several PAHs. It should be noted that the surface on which the PAHs are adsorbed varies in the different studies. We plotted the adsorption energy normalized by the number of carbon atoms $E_{\mathrm{des}} / N_{\mathrm{C}}$ as a function of $N_{\mathrm{H}} / N_{\mathrm{C}}$ in Fig. A.3. The adopted law is

$E_{\text {ads }} / k=\left(482 \times\left(N_{\mathrm{C}}-N_{\mathrm{H})}\right)+\left(946 \times N_{\mathrm{H}}\right) \mathrm{K}\right.$,

where $N_{\mathrm{C}}$ is the number of carbon atoms of the PAH and $N_{\mathrm{H}}$ is the number of hydrogen. $E_{\mathrm{CC}} / k(=482 \mathrm{~K})$ is the fitted desorption energy per graphene-like carbon, that is carbon atoms not attached to hydrogen and $E_{\mathrm{CH}} / k(=946 \mathrm{~K})$ is the fitted energy per benzene-like carbon and its adjoining $\mathrm{H}$-atom. Graphenelike carbons are $\mathrm{C}$-atoms with three covalent bonds with carbons, whereas benzene-like carbon have two covalent bonds with carbons and one bond with a hydrogen atom. Graphenes are PAHs where all the hydrogens have been stripped away. The value for $E_{\mathrm{CC}} / k$ is consistent with the measured range of adsorption energies of graphene on amorphous $\mathrm{SiO}_{2}$, which lies between 450 and $1685 \mathrm{~K}$ per carbon (Thrower et al. 2013; Kumar et al. 2016). The adsorption energies are also consistent with the theoretical values of Mészár et al. (2013).

The fitting formula is valid for PAH made of up to 100 carbon atoms. For bigger PAHs, the formula gives values that are larger than the heat of vaporization of graphite of $\Delta H_{\mathrm{f}} / k=86240 \mathrm{~K}$, Fig. A.4 (Pierson 1993). For circumcoronene, the estimated desorption energy is $34380 \mathrm{~K}$. A simple way to estimate the condensation temperature $T_{\text {cond }}$ is to balance the adsorption with the thermal desorption

$$
\begin{gathered}
\sigma_{\text {dust }} n_{\text {dust }} n_{\mathrm{PAH}} S_{\mathrm{PAH}} \sqrt{\frac{8 k T_{\text {cond }}}{\pi m_{\mathrm{PAH}}}}= \\
n_{\mathrm{PAH} \#} v_{\mathrm{osc}} \exp \left(-E_{\text {des }} / k T_{\text {cond }}\right),
\end{gathered}
$$


I. Kamp et al.: Consistent dust and gas models for protoplanetary disks. II.


Fig. A.2. PAH condensation temperature for anthracene $\left(\mathrm{C}_{14} \mathrm{H}_{10}\right)$ and circumcoronene $\left(\mathrm{C}_{54} \mathrm{H}_{18}\right)$ assuming three different grain radii.

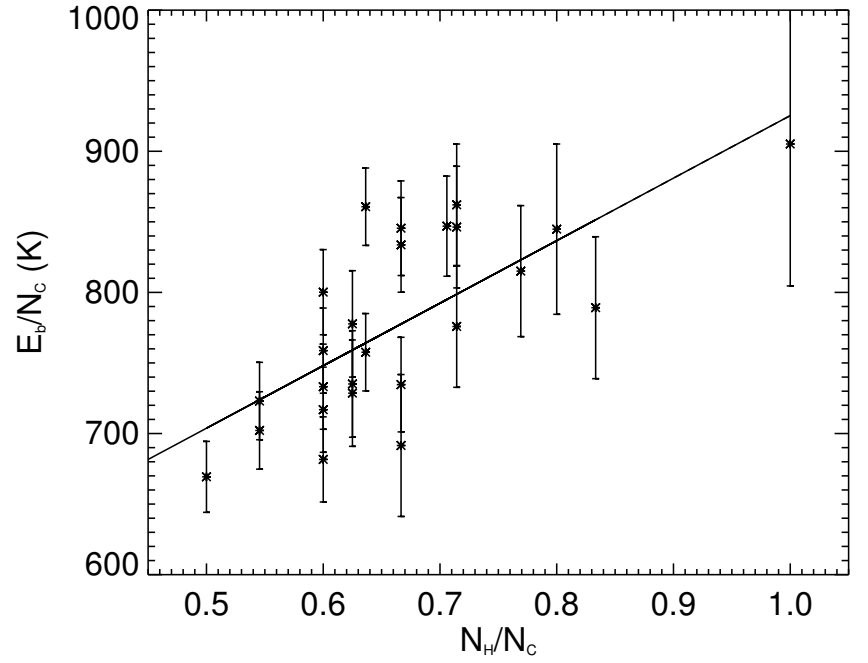

Fig. A.3. PAH binding energy normalized to the number of carbon atoms.

where the exponential prefactor is (Aikawa et al. 1996)

$v_{\mathrm{osc}}=\sqrt{\frac{2 n_{\mathrm{surf}} E_{\mathrm{des}}}{\pi^{2} m_{\mathrm{PAH}}}} \mathrm{s}^{-1}$.

$S_{\text {PAH }}$ is the sticking coefficient for PAH molecules and $n_{\text {PAH }}$ and $n_{\text {PAH\# }}$ are the number density of PAH in the gas phase and adsorbed on surfaces respectively. The number of surface adsorption sites is assumed to be $n_{\text {surf }}=1.5 \times 10^{15} \mathrm{~cm}^{-2}$ for grains with a radius of $0.1 \mu \mathrm{m}$. The average number of dust grains in the disk is

$$
\begin{aligned}
n_{\mathrm{d}} & =\frac{2.2 \mathrm{amu} n_{\mathrm{H}}}{(4 / 3) \pi \rho_{\mathrm{d}}\left\langle a^{3}\right\rangle \delta} \\
& \approx 2.907 \times 10^{-15} n_{\mathrm{H}}\left(\frac{\mu \mathrm{m}^{3}}{\left\langle a^{3}\right\rangle}\right)\left(\frac{100}{\delta}\right),
\end{aligned}
$$

where $\delta$ is the gas-to-dust mass ratio which is assumed to be 100. We have assumed a silicate mass density of $3.0 \mathrm{~g} \mathrm{~cm}^{-3}$. The balance between adsorption and thermal desorption for a gas density of $10^{10} \mathrm{~cm}^{-3}$, a grain radius of $1 \mu \mathrm{m}$, a gas-to-dust mass ratio of 100 , and assuming $n_{\mathrm{PAH}}=n_{\mathrm{PAH} \#}$ and a sticking coefficient of unity, leads to a condensation temperature for circumcoronene of $\sim 710 \mathrm{~K}$. In disks, PAHs should stick onto silicate grains and to each other. The condensation temperature for

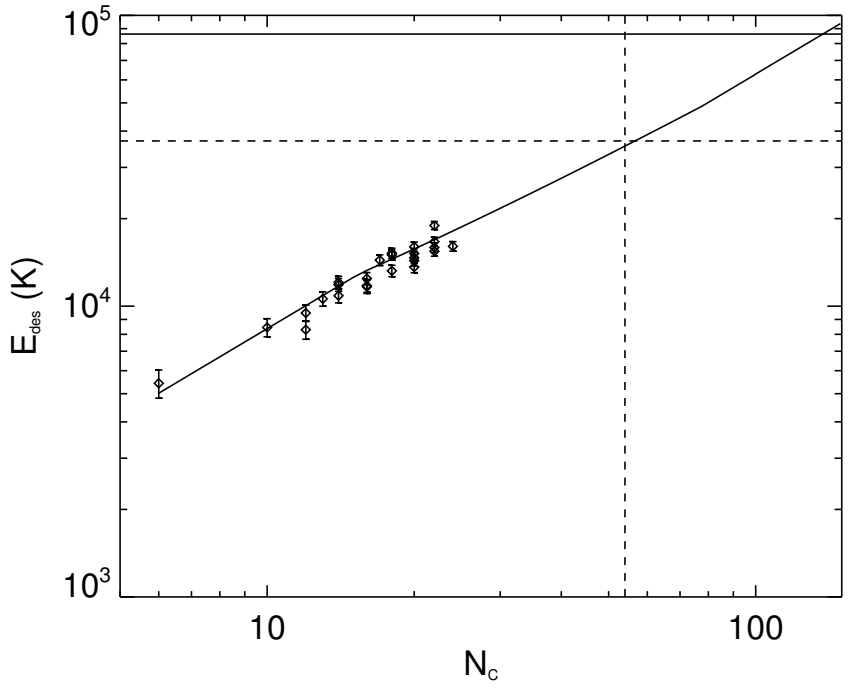

Fig. A.4. PAH desorption energy. The horizontal line corresponds to the limit imposed by the heat of vaporisation of graphite. The dashed-lines designate the desorption energy for circumcorene $\left(N_{\mathrm{C}}=54\right)$.

anthracene and circumcoronene is shown in Fig. A.2. The desorption of PAHs occurs thermally, induced by cosmic ray hits on the grains, and by absorption of a UV photon. We assumed a yield of $10^{-3}$ per absorbed photon for the photodesorption and a standard cosmic-ray induced desorption similar to the other ice species. The encounter between two PAHs can also result in the formation of clusters, which may subsequently grow by further accretion of PAHs. However, this mechanism is not accounted for in our current model.

\section{A.7. X-ray chemistry}

The X-ray chemistry in ProDiMo is described in detail in the appendix of Meijerink et al. (2012). Abbreviations for the references are listed in Table A.1.

The individual atomic ionization cross sections are used to derive the molecular dissociation rate from the individual ionization rates using the relative weight difference. If the difference in atomic weight between the components of the molecule is large, the cross section of the heavier one is used. If the difference is small, the cross sections are combined (Aresu et al. 2011). An example is the reaction CO + XPHOT which can lead 
to $\mathrm{C}^{2+}+\mathrm{O}, \mathrm{C}^{+}+\mathrm{O}^{+}$, or $\mathrm{C}+\mathrm{O}^{2+}$, so that the total cross section is the sum

$\sigma_{\mathrm{CO}}=\frac{1}{3} \sigma_{\mathrm{C}}+\frac{1}{6}\left(\sigma_{\mathrm{C}}+\sigma_{\mathrm{O}}\right)+\frac{1}{3} \sigma_{\mathrm{O}}$,

where $\sigma_{E l}$ is the ionization cross sections of the element, in this case $\mathrm{C}$ and $\mathrm{O}$.

More detailed explanations and discussions of rates can be found in Ádámkovics et al. (2011). The di-electronic recombination rates are from tables of Landini \& Fossi (1991), Badnell et al. (2003), Badnell (2006), Zatsarinny et al. (2003) and subsequent papers of this series. In case of X-rays, the high temperature di-electronic recombination rates get added to the radiative recombination rates taken from UMIST. The two elements $\mathrm{Ne}$ and $\mathrm{Ar}$ have only di-electronic recombination rates currently available. We include here also charge exchange reaction of $\mathrm{Ar}$ and $\mathrm{Ne}$ with water, $\mathrm{O}_{2}, \mathrm{CO}, \mathrm{N}_{2}, \mathrm{CH}_{4}, \mathrm{NH}_{3}, \mathrm{CO}_{2}$, and NO. In addition we consider charge exchange between $\mathrm{He}^{+}$ and $\mathrm{Ne}$.

\section{Appendix B: How $E_{\text {ads }}$ affects line fluxes}

We show in Figs. B.1 to B.3 how models with different sets of adsorption energies (Aikawa, GH06, UMIST2012 and temperature-dependent $E_{\text {ads }}$ ) affect our selection of line fluxes.
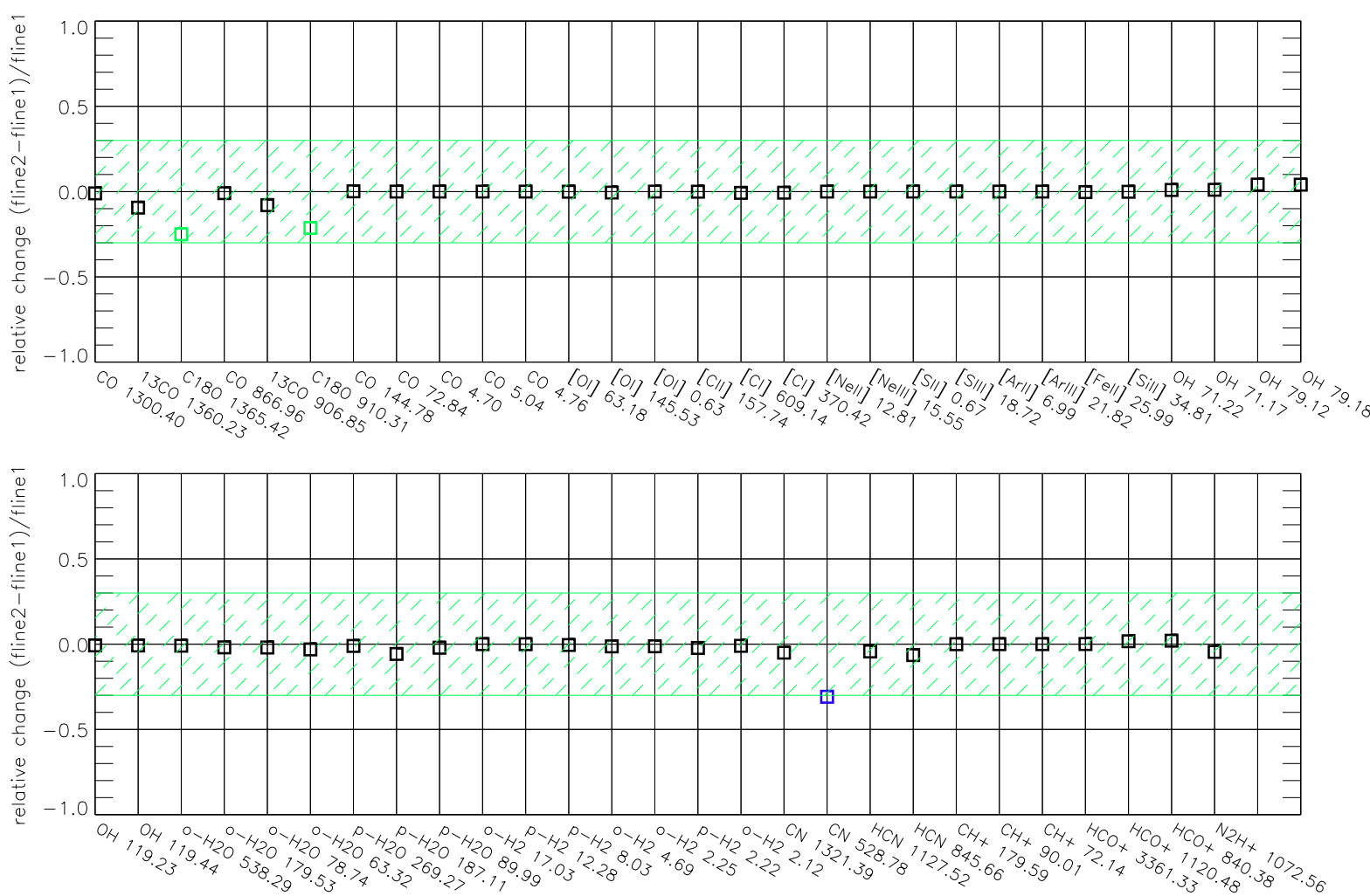

Fig. B.1. Comparison of line fluxes for two sets of adsorption energies: Aikawa (fline1, model 1) and GH06 (fline2, model 5). Black and green squares denote differences of less than $25 \%$ and less than a factor two respectively, blue squares and red triangles denote differences larger than a factor three and ten respectively. 
I. Kamp et al.: Consistent dust and gas models for protoplanetary disks. II.
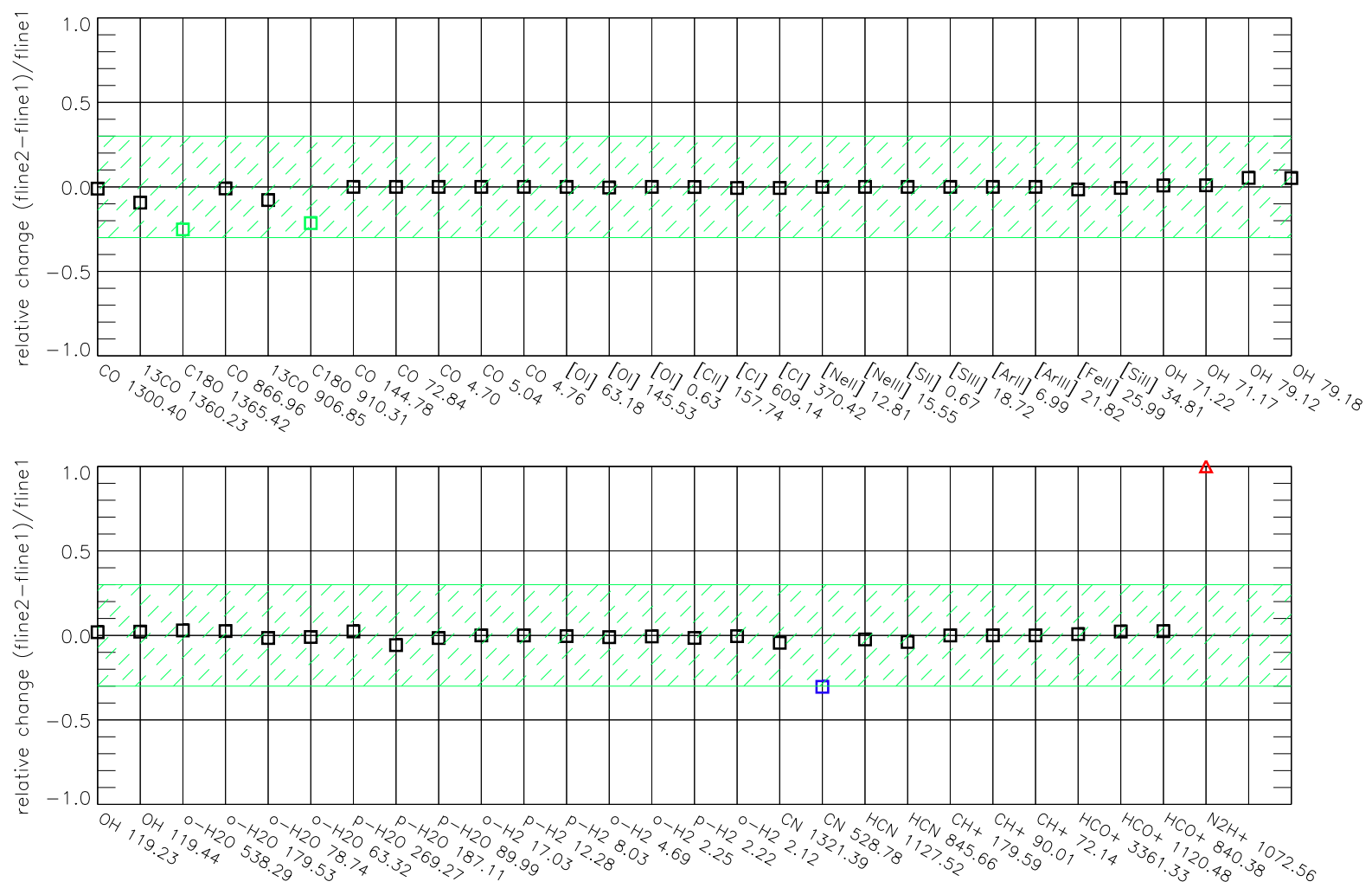

Fig. B.2. Comparison of line fluxes for two sets of adsorption energies: Aikawa (fline1, model 1) and UMIST2012 (fline2, model 6). Black and green squares denote differences of less than $25 \%$ and less than a factor two respectively, blue squares and red triangles denote differences larger than a factor three and ten respectively.
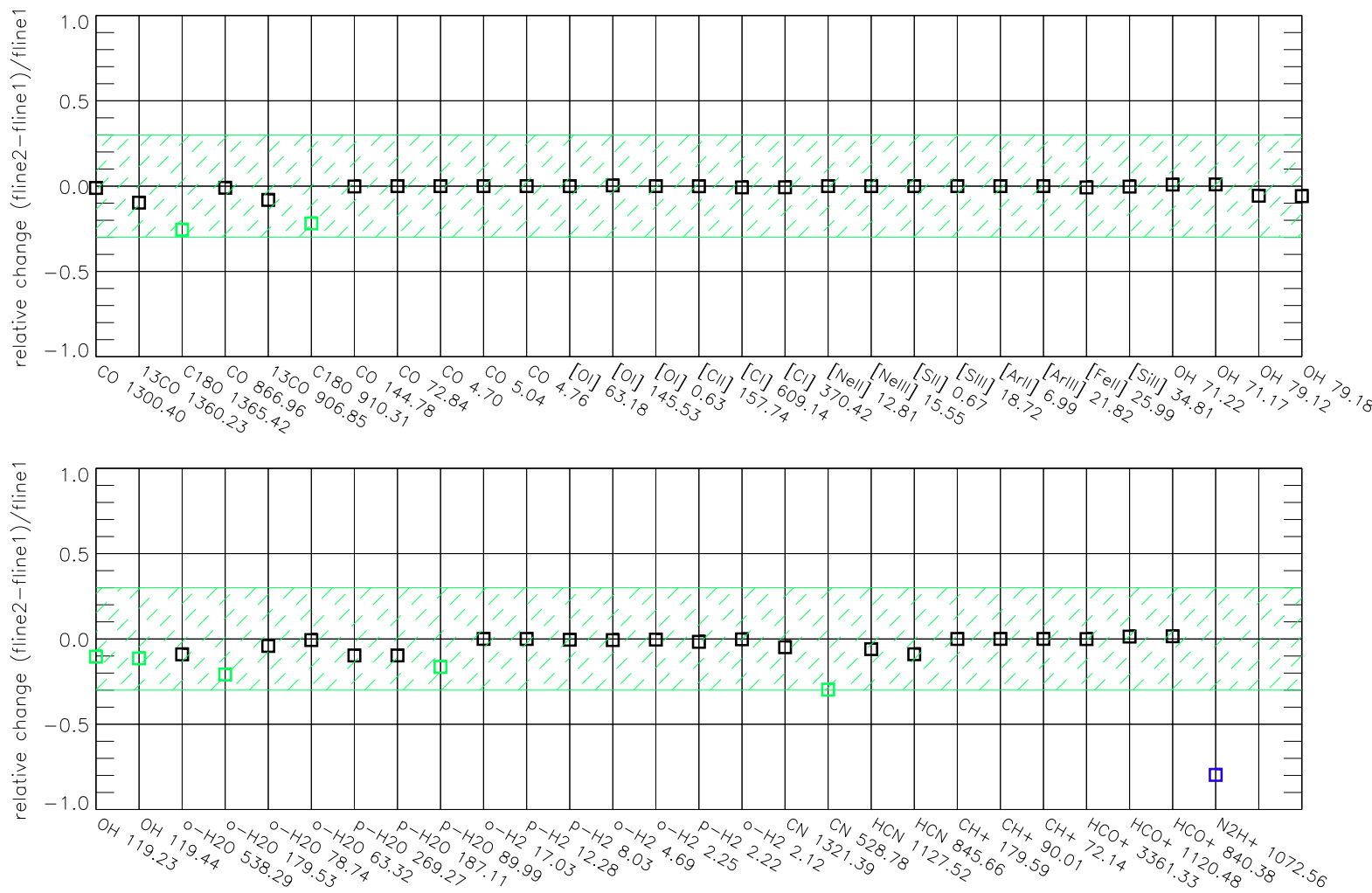

Fig. B.3. Comparison of line fluxes for two sets of adsorption energies: Aikawa (fline1, model 1) and $T$-dependent adsorption energies (fline2, model 7). Black and green squares denote differences of less than $25 \%$ and less than a factor two respectively, blue squares and red triangles denote differences larger than a factor three and ten respectively. 